\title{
Sobre los sustantivos perródromo, galgódromo, cinódromo y canódromo: rivalidad léxica, distribución geográfica y difusión
}

\author{
On the nouns perródromo, galgódromo, cinódromo and canódromo: \\ lexical rivalry, geographical distribution, and diffusion
}

\author{
David Prieto García-Seco \\ Universidad de Murcia \\ davidprieto@um.es
}

ORCID iD: https://orcid.org/0000-0002-7417-2791

RESUMEN: Este trabajo estudia monográficamente las voces perródromo, galgódromo, cinódromo y canódromo. Para ello, en primer lugar, se consideran las denominaciones utilizadas en distintas lenguas para referirse al lugar donde se celebran carreras de galgos, con especial atención a las lenguas romances (cynodròme en francés, cinodromo en italiano, canídromo en portugués, etc.). Posteriormente, se muestran los diversos sinónimos que circularon en español para designar dicha pista y se expone la pugna que tuvo lugar entre ellos. Finalmente, se examina cada uno de los sustantivos estudiados atendiendo a su difusión y su distribución geográfica.

Palabras clave: historia del léxico español, rivalidad sinonímica, perródromo, galgódromo, cinódromo, canódromo.

ABSTRACT: This article studies in depth the nouns perródromo, galgódromo, cinódromo and canódromo. To this end, the terms used to refer to the greyhound racing track in different languages are first analysed, paying special attention to Romance languages (cynodròme in French, cinodromo in Italian, canídromo in Portuguese, etc.). Then, the various synonyms used in Spanish to refer to that place are described, highlighting the competition among these forms. Finally, the article examines the diffusion and geographical distribution of each of the nouns under study.

Keywords: history of Spanish lexicon, synonyms rivalry, perródromo, galgódromo, cinódromo, canódromo. 


\section{INTRODUCCIÓN}

Poco antes de los años veinte del siglo pasado surgieron en Estados Unidos, con las características modernas que hoy conocemos, las carreras de galgos tras una liebre artificial, y en poco tiempo se ganaron el aplauso entusiasta del público. El extraordinario éxito que esta modalidad deportiva cosechó en este país motivó que en apenas cinco o seis años diversos países hispanoamericanos y europeos decidieran importarla. En Inglatera fue tal la acogida del público que en un breve periodo se construyeron decenas de pistas para el desarrollo de esta actividad, denominadas en inglés, principalmente, dog track. La afición a estas carreras se fue extendiendo, posteriormente, a otros países europeos, donde el mismo recinto fue bautizado con diversos nombres: cynodròme en francés, cinodromo en italiano, canídromo en portugués, etc. El gusto por las carreras de galgos también llegó a España y a otros países de habla hispana e, igualmente, hubo de buscarse una denominación para el lugar en que se realizaban tales competiciones.

El objetivo específico de este artículo es estudiar monográficamente las voces perródromo, galgódromo, cinódromo y canódromo, atendiendo a los cinco siguientes aspectos: la etimología, las primeras documentaciones, la difusión, la distribución geográfica y la rivalidad léxica que se observa entre los sinónimos analizados.

Para alcanzar dicho objetivo se ha recurrido a distintas fuentes de información léxica, que podemos dividir en tres grupos: diccionarios, corpus y otras fuentes de información. Con el objeto de trazar la trayectoria histórica de las voces consideradas, en primer lugar, nos hemos servido de diversos diccionarios tanto del español como de otras lenguas. No obstante, importa indicar que, en relación con las voces que nos ocupan, este tipo de herramientas filológicas resulta ostensiblemente insuficiente, puesto que el uso que han tenido los sustantivos perródromo, galgódromo, cinódromo y canódromo no se refleja fielmente en el registro lexicográfico. El NTLLE, por ejemplo, tan solo ofrece resultados sobre la voz canódromo; según este recurso, se incluyó en el diccionario usual de la Academia en la edición de 1970, y llega hasta nuestros días ${ }^{1}$. En cambio, el sustantivo canódromo — como podrá comprobarse más adelante (§ 3.4)— comenzó a circular en español en los años veinte del siglo pasado, cuando en inglés se empezaba a utilizar, entre otros, el compuesto dog track.

La segunda fuente a la que hemos acudido son los distintos corpus que pueden consultarse en línea. Fundamentalmente, se han manejado los corpus académicos (CNDH, CORDE, CORPES, CREA), aunque también se han utilizado otros elaborados por distintas instituciones (por ejemplo, el CORDIAM). Al término del trabajo se recogen todos los corpus de que nos hemos servido, consultados durante los meses de marzo y abril de 2018.

${ }^{1}$ Según el NTLLE, también recoge dicho sustantivo el Diccionario manual e ilustrado de la lengua española (3. ${ }^{a}$ ed., 1983). 
En tercer lugar, se han utilizado otras fuentes que ofrecen información relevante para nuestro objeto de estudio. Al respecto, hay que mencionar, por su riqueza léxica, el Fichero general de la Academia, consultable telemáticamente desde marzo de 2012. No obstante, debemos encarecer, fundamentalmente, otros recursos de acceso en línea que en los últimos años están prestando un servicio extraordinario a los estudios filológicos, especialmente de corte diacrónico; nos referimos, entre otros, a las bibliotecas y hemerotecas digitales y a la página de Google Libros. Estas últimas fuentes, que permiten la búsqueda y localización de voces en textos que previamente han sido digitalizados y sometidos a un proceso de OCR (Optical Character Recognition), ofrecen una información léxica de cuya consulta, sin duda alguna, no puede abstraerse quien desee abordar hoy día el estudio del léxico español desde una perspectiva histórica. El lector tendrá la oportunidad de comprobar la extraordinaria utilidad que tienen estos recursos para la historia del léxico y podrá constatar que sin ellos no habría sido posible describir el nacimiento de las voces estudiadas y su ulterior desarrollo.

Este trabajo está estructurado en tres apartados, además de la presente introducción. En $\S 2$ se ofrece una contextualización histórica de las carreras de galgos con liebre mecánica, desde sus inicios hasta la difusión posterior y su llegada a España. El apartado 3 constituye la parte principal del estudio. En primer lugar, se presentan algunas de las denominaciones que se propusieron inicialmente y se expone el debate que tuvo lugar en torno a ellas. En las cuatro siguientes secciones se abordan los aspectos mencionados de las voces perródromo (\$ 3.1), galgódromo (\$ 3.2), cinódromo (\$ 3.3) y canódromo ( $\$ 3.4$ ). Cierran el estudio unas conclusiones.

\section{CONTEXTO HISTÓRICO: INICIOS Y PROPAGACIÓN DE LAS “CARRERAS DE GALGOS CON LIEBRE MECÁNICA"}

Parece ser que en 1876 tuvieron lugar en Inglaterra ciertas carreras de galgos tras una liebre artificial; estos antecedentes, sin embargo, no gozaron de éxito alguno y pronto se abandonaron ${ }^{2}$. Los primeros pasos que condujeron en

2 "There are on record particulars of a meeting which took place in a field near the Welsh Harp, Hendon, in 1876, for the purpose of demonstrating a form of greyhound racing almost exactly similar in principle to the modem form. The dogs were raced after an artificial hare which was drawn, by means of a windlass, along a rail laid in the grass over a straight track of 400 yards. But the innovation received insufficient encouragement to keep it alive. It seems that public ideas of sport at that time were not satisfied by the mere racing of greyhounds, for when a year or two later enclosed coursing was introduced the objection was raised that it was more like racing than coursing, and it soon died out. Coursing men realized that sheer racing is inimical to the traditional principles of the sport" (The Encyclopadia Britannica, 1932, vol. 10, p. 886a). Wilcox (2001: 23) afirma: "In 1876, two new types of Greyhound events were held in England. The first event 
derechura a las carreras de perros tal y como hoy día se reconocen prototípicamente - desarrolladas en un circuito oval o, más precisamente, en un rectángulo redondeado, con dos rectas y dos curvas, en el que los animales persiguen a una liebre artificial - se dieron en Estados Unidos a partir de 1912, cuando el estadounidense Owen Patrick Smith inventó la liebre mecánica, con la que daba respuesta a una demanda social que denunciaba la muerte de liebres que se producía en la tradicional caza con galgos en campo abierto (Hartwell, 1980: 19; Genders, 1981: 271; Temple, 2011: 12).

Animal rights activists stifled growth in the competition, however, as they protested the killing of jackrabbits that were used in the events. Their protests led dog enthusiasts to seek out alternative, nonanimal lures or bait. Owen Patrick Smith answered their call. He experimented with stuffed jackrabbits that he mounted on motorcycles. By 1920, he had received a patent for an artificial mechanical lure that he used in Salt Lake City (Thompson, 2015: 105).

En 1919 Smith abrió la primera pista oficial de carreras en Emeryville (California), que llamó "Blue Star Amusement" (Wilcox, 2001: 23; Thompson, 2015: 104-105), y en pocos años se construyeron en Estados Unidos alrededor de sesenta canódromos. Smith, asimismo, fundó la International Greyhound Racing Association, dedicada, en colaboración con el American Kennel Club, a registrar los perros y regular las carreras (Thompson, 2015: 105b).

En 1926 el deportista norteamericano Charles A. Munn —en asociación con el mayor Lyne Dixson y el brigadier general canadiense Alfred Cecil Critchley - introdujo en Inglaterra la pista oval y la liebre mecánica (Levinson y Christensen, 1999: 86a). El 24 de julio tuvo lugar la primera carrera oficial en el estadio de Belle Vue (Gorton, Manchester) (Genders, 1981: 34, 264-265), y en poco tiempo las carreras de galgos con liebre mecánica contaron con miles de aficionados, sobre todo, de clases populares, quienes, al no poder asistir a las exclusivas carreras de caballos, veían, sin duda, el nuevo deporte como un entretenimiento accesible en el que, además, podían hacer sus apuestas (Knight, 2003: 14; Levinson y Christensen, 1999: 86a).

(1) [1927] Greyhound racing, brought to England from Florida by the American sportsman, Charles A. Munn, has taken the British Isles by storm. Within the year since it was first introduced at Manchester this sport has become a rival of horse racing, motion pictures and the legitimate theatres. (The New York Times, 22 de agosto de 1927, p. 13c).

\footnotetext{
was called a park course. This fenced-in course was only 800 yards (732 meters) long. Its short length allowed more people to see the entire event. Dogs were judged on a point system similar to regular coursing. The other event was the first Greyhound track race. Organizers set up a long, straight track. The dogs chased after a toy rabbit called a lure. But the dogs did not actually catch the moving toy. Dogs won based on how fast they chased the lure. Both park coursing and track racing were unsuccessful in England at the time".
} 
Según algunos medios, las apuestas fueron el motivo principal del éxito cosechado por este deporte; sin ellas — se asegura en algunos periódicos de la época- las carreras de galgos no habrían tenido desarrollo alguno.

(2) [1927] Sobre la afición que los ingleses tienen hacia perros y caballos, el espectáculo contó desde el principio con un aliciente muy del gusto británico: las apuestas. Con ellas las carreras estaban salvadas. [...] Casi todos los organizadores, al adoptar la liebre mecánica que corre deslizándose por un carril ante las narices mismas de los engañados perros, hicieron costosas instalaciones para dar espectáculo nocturno, y así, empleados y obreros, cuando salen de sus obligaciones, pueden ir a las carreras, que empiezan entre siete y siete y media de la tarde, en vez de marcharse al cinematógrafo, al bar o a cualquier otra distracción. (Blanco y Negro, 20 de noviembre de 1927, p. [72b]; Abc; cfr. texto 52).

En poco tiempo el deporte experimentó en Inglaterra una extraordinaria acogida: a fines de 1926 contaba con unos 30000 espectadores. Este éxito motivó la construcción de otros muchos canódromos en varias ciudades y pueblos británicos; en 1927 había unas cuarenta pistas.

(3) [1927] Puede afirmarse que las carreras de galgos han alcanzado el apogeo de la popularidad. [...]. Se observa que tanto las carreras de caballos como el fútbol comienzan a temer las consecuencias del entusiasmo del público por las carreras de galgos. Estas han invadido ya todos los Centros considerados como fortalezas inexpugnables del fútbol británico, constituyéndose Sociedades para la explotación de los galgódromos de Liverpool, Brighton, Leicester, Leeds, Cardiff, Bradford, Sunderland, Glasgow, Blockpool, Bolton, Burnley, etc., llegando a 40 el total de las Compañías registradas en Inglaterra. ( $A b c, 17$ de agosto de 1927, p. 25c; cfr. textos 18 y 19).

En 1927 aún no habían llegado las carreras de galgos a España, pero, naturalmente, la prensa nacional se hacía eco del acontecimiento social que tal deporte suponía en Inglaterra; ello provocó que en España naciera un debate en torno a la oportunidad de introducir un nuevo deporte que gozaba ya de un éxito extraordinario en Inglaterra ${ }^{3}$. En un principio no fueron pocas las voces

${ }^{3}$ Según un informe de diciembre de 1933 redactado por el Juez de Instrucción número 10 de Madrid Mariano Luján —en el que, en relación con las carreras de galgos, denuncia delitos de asociación ilícita, juego prohibido, malversación, estafa, prevaricación y falsedad, en torno al mes de diciembre de 1926 (es decir, cuando apenas habían transcurrido cinco meses desde la llegada del nuevo deporte a Inglaterra)—, "varias personas concibieron, con manifiesta intención de lucro, la implantación en España de la explotación, con carácter de exclusiva, de las carreras de galgos en pista con apuestas mutuas, mediante un aparato o liebre eléctrica [en cursiva en el original], cuyos grandes rendimientos en el extranjero conocían. Dichas personas, asimismo, conocían la imposibilidad legal de establecer ese negocio sin una autorización del Gobierno, de difícil consecución a la sazón, dada la índole del asunto, por la rigurosa prohibición del juego, confiando, sin embargo, a ese efecto la influencia que la elevada posición social 
que se opusieron, con unas u otras razones, a la importación del "colmo de los deportes simplistas" (cfr. textos 15 y 20).

(4) [1927] España no quiere galgódromos. Una petición desestimada [título de la noticia] / No se dirá que andamos tardos en imitar las cosas del extranjero, las malas, claro, porque en las buenas no nos damos tanta prisa. Han bastado, en efecto, unas cuantas informaciones inglesas y unas pocas fotografías de canídromos, dando idea de muy buenas entradas, para que se haya acudido al Gobierno en súplica de autorización para implantar el nuevo deporte de carreras de galgos y liebre mecánica, con apuestas mutuas. [...] Nos admiramos de que en Inglaterra, donde el nuevo deporte ha nacido, despierte tanto entusiasmo y proporcione tan buenas ganancias a los empresarios de galgódromos o canídromos. [...] La afición a la caza de la liebre con galgos en campo libre quedaría desfigurada por completo en los canídromos. (Diario melillense El Telegrama del Rif, 7 de diciembre de 1927, p. $1 e-f ; \mathrm{BVPH})$.

(5) [1928] He aquí que el Gobierno español se ha opuesto a la introducción en España del deporte que este verano adquiriera en Inglaterra la más inusitada de las bogas. [...] No hay todavía [en España] un interés social demasiado claro en mejorar la raza perruna solo en sus aptitudes de velocidad. Y si la clase de galgos corredores (de glorioso abolengo, ciertamente, en la tradición española) necesita de ejercicios que afinen su instinto y robustezcan su elástica musculatura, habrá de ser en la carrera a campo abierto, tras la liebre auténtica, veloz y cauta, no tras la mixtificación monstruosa que se desliza sobre el carril desenfrenado, bajo la luz artificial de White Hall y en una distancia estereotipada de 525 metros (una vuelta de pista), que es, en fin de cuentas, la seguridad de una monotonía inaguantable. (Estampa. Revista gráfica y literaria de la actualidad española y mundial, 24 de enero de 1928, pp. [12-13]; HDBN).

A pesar de la acaso precipitada negativa inicial, en torno al mes de abril de 1929 el debate, inevitablemente, se avivó en las tertulias de los aficionados a la caza con galgos en campo abierto, donde todavía había algunos galgueros que seguían considerando que los galgos no estaban hechos para ese deporte y, en consecuencia, se reafirmaban en mantener la caza de liebres, que tenía una tradición centenaria en España ${ }^{4}$, tal y como se practicaba hasta entonces en la Península. No obstante los rechazos iniciales, las carreras de galgos en pista, que seguían extendiéndose por Europa e incluso por otros continentes, llegaron a España un año después. El 12 de abril de 1930 se inauguraron públicamente las carreras en el

\footnotetext{
y política de alguna de las personas dichas pudiera ejercer sobre el Gobierno (sesiones del Consejo de Stadium Metropolitano S.A. de 7 de diciembre de 1926 y 6 de julio de 1927 y citas posteriores)" (Zavala, 2013: 465-466).

${ }^{4}$ Entre muchos otros testimonios sobre este tipo de caza, podemos recordar uno de Cervantes (1613: $118 \mathrm{r}^{\circ}$ ), quien ponía en boca del licenciado Vidriera estas palabras: "La caça de liebres dixo que era muy gustosa, y más quando se caçaua con galgos prestados" (Novela del licenciado Vidriera).
} 
Stadium madrileño ${ }^{5}$, si bien unos días antes se habían celebrado diversas carreras de prueba, con la asistencia del rey Alfonso XIII (véase la Figura 1):

(6) [1930] El "Club Deportivo Galguero", Sociedad naciente que se propone intensificar, por cuantos medios estén en su mano, la afición española a los galgos y el mejoramiento consiguiente de nuestra producción, y uno de cuyos fines (pero no el único) es la implantación en la Península de las carreras de galgos en pista [...], celebró el día 2 de los corrientes, en el Stadium, las primeras pruebas oficiales de estas carreras, pruebas que fueron presenciadas por S. M. el Rey y por una gran mayoría de los galgueros de Madrid y su provincia, y algunos curiosos. A la fiesta solo dejaron de concurrir, entre los galgueros de valía, contados elementos, y algunos de estos que brillaron por su ausencia lo hicieron, sin duda, influenciados aún por el prejuicio, injustificado, de que estas carreras se opongan a la afición a la liebre en el campo. (Heraldo Deportivo, 15 de abril de 1930, p. $141 a ; \mathrm{HDBN})^{6}$.

Nótese que, recién llegado el deporte a España, aún resonaba la discrepancia de los galgueros que no veían con buenos ojos la nueva modalidad deportiva. Parece ser que la importación de este deporte se debió a la iniciativa de dos aristócratas, el duque de Alba y el marqués de Villabrágima, "que, después de presenciar algunas carreras en los cinódromos ingleses, apreciaron con clara visión el arraigo que en España puede tener este deporte" (Revista Cinegética Ilustrada, n. ${ }^{\circ} 82$, abril de 1930, p. $15 b$; HDBN). Otros medios de la época otorgan también un papel relevante al rey en la importación de las carreras de galgos. En la revista Mujeres Españolas se recoge una entrevista - llamada "Un nuevo deporte en España. Carreras de Galgos en el Stadium"- al secretario del Club Deportivo Galguero y director del Stadium, el abogado Joaquín Losada Pinedo ${ }^{7}$. Además de poner de relieve el éxito cosechado por las carreras celebradas en Madrid, el secretario afirmaba que la introducción de este tipo de carreras en España fue iniciativa del rey Alfonso XIII:

(7) [1930] — ¿A quién se debe esta iniciativa?

-En primer lugar, a nuestro Soberano. Su Majestad el Rey vio últimamente en Londres, en unión del Duque de Alba, carreras de galgos y quedó tan complacido que expuso su opinión de que en España fuera ensayado este

\footnotetext{
5 "La inauguración del canódromo, verificada ayer, llevó al Stadium una gran concurrencia. Corriéronse seis pruebas, una de saltos" (Madrid, $A b c, 13$ de abril de 1930, p. 51b; véase también Revista Cinegética Ilustrada, n. ${ }^{\circ}$ 82, abril de 1930, p. 16a; HDBN, y el texto 21).

6 “Ayer tarde, en el Stadium, se celebró la inauguración de las carreras de galgos tras de liebres mecánicas. La entrada fue exclusivamente por invitación. Asistieron el Rey, numerosos palatinos, aristócratas y también los directivos del Club Galguero, entre ellos el marqués de Villabrágima" (Las Provincias. Diario de Valencia, 3 de abril de 1930, p 6d; BVPH).

7 Quien había sido comisionado para copiar el formato inglés de las carreras (número de carreras, premios en metálico, apuestas, jueces de salida y de llegada, handicappers, etc.).
} 
deporte (Mujeres Españolas, n. ${ }^{\circ}$ 66, 25 de mayo de 1930, p. 20a; BVPH) ${ }^{8}$.

Como había sucedido en otros países, las carreras de galgos rápidamente se pusieron de moda en España: "Este deporte — puede leerse en El Castellano (26 de noviembre de 1930, p. 3a; BVCLM) — es ahora el último grito, el postrer bocinazo de la moda, algo que va apasionando tanto como las carreras de caballos, el fútbol y los toros". La prensa de la época hablaba de "gran concurrencia", "numerosa concurrencia", "gran interés", "gran animación”, "tanta animación como en el día anterior", "gran afición”, etc. El interés creciente por este nuevo deporte también puede advertirse en el espacio que los medios escritos le dedican, que paulatinamente es mayor. A las carreras no solo acudía la gente humilde, obreros, sino también aristócratas, que llevaban a sus galgos para que compitieran con otros (cfr. texto 21). Entre muchos otros, en las primeras carreras participaron los perros del duque de Alburquerque, del duque de Pastrana, del marqués y la marquesa de Villabrágima, de la marquesa de Casa López, del conde de Velayos o del conde de Lérida.

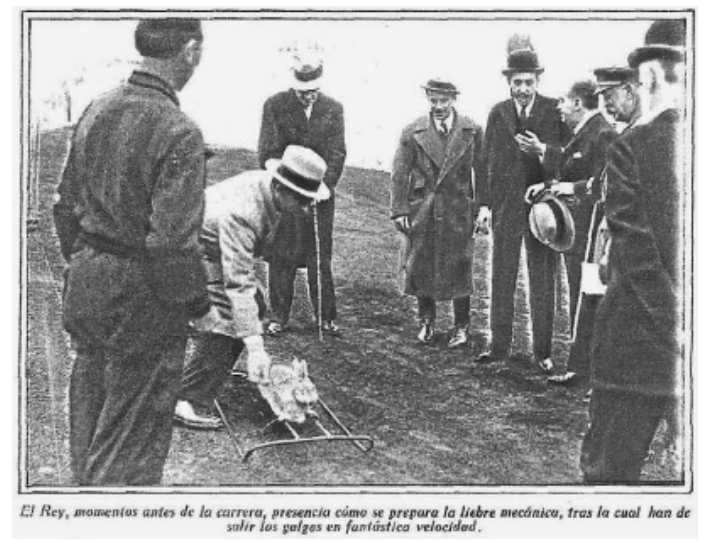

FIGURA 1.-Estampa. Revista gráfica y literaria de la actualidad española y mundial, 8 de abril de 1930, p. [44].

La afición por la carreras fue extendiéndose a otras ciudades españolas, en las que se construyeron nuevas pistas: Palma de Mallorca (antes de abril de 1931, según Heraldo de Madrid, 25 de abril de 1931; HDBN), Sevilla (antes de abril de 1931, ibíd.), Valencia (6 de diciembre de 1931; cfr. textos 35, 36 y 63), Barcelona

\footnotetext{
${ }^{8}$ En La Vanguardia leemos: "Terminadas las carreras el Club Deportivo Galguero obsequió con un «lunch» a S. M. y demás invitados. Durante el agasajo nuestro compañero [periodista] don Manuel Domingo fue presentado a S. M. el Rey, quien le dijo que esperaba que el nuevo deporte tuviese gran aceptación en España, como la tiene en Inglaterra y en los Estados Unidos. - Yo -agregó don Alfonso- asistí por primera vez en esta clase de carreras en Londres y me entusiasmaron y es de esperar que al público español le ocurra lo mismo" (3 de abril de 1930, p. 21c).
} 
("Canòdrom-Park", inaugurado el sábado 19 de mayo de 1934'), Cartagena (13 de agosto de $1934^{10}$ ), Murcia (7 de abril de $\left.1935^{11}\right)$, Las Palmas de Gran Canaria (“Campo España”, 1935 12 ), Sevilla (8 de diciembre de $1936^{13}$ ), etc.

\section{RIVALIDAD LÉXICA DE LOS SUSTANTIVOS PERRÓDROMO, GALGÓDROMO, CINÓDROMO Y CANÓDROMO}

Expuesta una breve trayectoria histórica de este deporte desde sus inicios hasta su llegada a España, abordaremos diversas cuestiones léxicas en torno a las voces que nos van a ocupar: perródromo (§ 3.1), galgódromo (\$ 3.2), cinódromo $(\S 3.3)$ y canódromo (\$ 3.4). Para designar la pista preparada convenientemente para las carreras de galgos el inglés utiliza varios nombres compuestos. Principalmente, se emplea en esta lengua dog track, aunque también se usa dog-racing track o los compuestos formados por el hipónimo greyhound en lugar del hiperónimo dog: greyhound track y greyhound racetrack ${ }^{14}$. El nacimiento de este deporte y, más tarde, su llegada a

9 "El cinódromo barcelonés / Ayer por la tarde se verificó la inauguración oficial del Canòdrom-Park, instalado en los antiguos terrenos de entrenamiento que el F. C. Barcelona poseía en la Travesera de Las Corts" (La Libertad, 20 de mayo de 1934, p. 8d; HDBN).

10 "La inauguración del Canódromo cartagenero con la celebración de su primera carrera de galgos ha dado motivo a un triunfo local" (diario cartagenero El Noticiero, 14 de agosto de 1934, p. 2c; AMC); "Cartagena, 13.- -Se ha celebrado la inauguración del cinódromo de esta población" (La Libertad, 14 de agosto de 1934, p. 9a; HDBN). Véase también el texto 69.

11 "Un canódromo en Murcia / Murcia 7. Se ha inaugurado en el campo de Zarandona un canódromo, asistiendo bastante público y cruzándose bastantes apuestas" (Abc, 9 de abril de 1935, p. 52a).

12 "Carreras de galgos / Ayer, festividad de San José, se celebró en el Campo España la segunda carrera de galgos" (Diario de Las Palmas, 20 de marzo de 1935, p. 3; HDBN); "Por la tarde del mencionado día 29 y en el Campo España se celebrará un festival regional, con desafíos de luchas canarias [...], concurso de cantos regionales y carreras de galgos" (diario santacrucero La Prensa, 19 de diciembre de 1935, p. 2a; BVPH).

13 “CANÓDROMO SEVILLANO.-(Piscina Los Remedios.) Inauguración, día 8, 3,15 tarde. A beneficio del Aguinaldo del Soldado. Seis grandes carreras. Importantes premios" ( $A b c$, ed. Andalucía, 8 de diciembre de 1936, 19c).

${ }^{14}$ En el primer suplemento (1933) de la primera edición de The Oxford English Dictionary se añadió el compuesto dog-track: «17. a. in ref. to greyhound racing, as dog-race, -racer, -racing, -track. [...] 1928 Observer 25 Mar. 16/6 The Ministry of Health has decided that Wimbledon must put up with a dog-track, however much the Council and inhabitants may resent it» $(O E D)$. Este suplemento no registra ninguno de los compuestos señalados formados con greyhound, si bien añade el compuesto greyhound racing, «a sport in which a dummy hare propelled mechanically round a set track is coursed by greyhounds». El suplemento del $O E D$ que comenzó a publicarse a partir de los años setenta mantiene, como primera documentación de dog-track, el texto de 1928 y, además, añade una segunda cita: «1958 Economist II Oct. 155/I A racecourse, a dog track, and thirty-nine pubs help the men to get through the $£ A 2,000$ a year that many of them have been earning». En este suplemento se producen algunas novedades respecto del suplemento de 1933: se recogen por primera vez los compuestos greyhound racecourse y greyhound racing track: «1926 Manch. Guardian 19 July 5/6 (Advt.), Greyhound races. Belle Vue racecourse, Manchester. Ibíd. 23 July 11/4 The Greyhound Racecourse, Kirkmanshulme Lane, Gorton, applied for an occasional licence to sell intoxicating drink. 
países de lengua española plantearon la necesidad de recurrir a un nombre con el que designar aquella pista. Desechada la utilización cruda del término inglés dog track, hubo quien se decantó por la traducción literal pista de carreras de perros:

(8) [1927] El nuevo deporte de carreras de perros ha demostrado ser extraordinariamente agradable al público. Hace poco más de un año que se inauguró en Manchester la primera pista de carreras de perros. [...] El gran Stadium de Wembley — familiar a todos cuantos visitaron la Exposición del Imperio Británico - ha sido comprado por un sindicato y se espera que dentro de unas semanas quede aquel convertido en una de las pistas de carreras de perros más hermosas del mundo, con acomodación para 90000 espectadores. (La Vanguardia, 22 de septiembre de 1927, p. 25d).

Con el objeto de satisfacer tal necesidad designativa en diversos países donde se hablaban lenguas romances se prefirió — con mucho mejor criterio - la creación de un término que estuviera en consonancia con la morfología de tales lenguas, de manera que se optó por diversos nombres compuestos: cynodrome en francés, cinodromo en italiano, canídromo (canódromo y cinódromo) en portugués, canòdrom (y cinòdrom) en catalán. He aquí dos de las posibilidades denominativas que el español tenía a su alcance, pero no fueron las únicas. En la revista Cosmópolis leemos lo siguiente:

(9) [1928] Un perródromo aristocrático en Londres. [...] En las [carreras] que los ágiles galgos persiguen velozmente a una liebre mecánica que sustituye a la auténtica. Así el amplio estadio de Wembley queda convertido circunstancialmente en perródromo. (Cosmópolis, abril de 1928, p. 64; BDMM).

Pese a la transparencia del término perródromo, que en español podría haber satisfecho perfectamente la necesidad designativa, el rechazo no se hizo esperar. En el diario La Época el escritor madrileño y colaborador asiduo de dicho periódico Luis Araujo Costa escribía, en la sección Los puntos sobre las ies, un artículo llamado "Cinódromo y no perródromo". Este autor lamentaba la utilización de la voz perródromo en aquella revista para designar el lugar donde se celebran carreras de perros:

(10) [1928] Como la palabra [perródromo] pudiera divulgarse en los países de lengua española, me permito apuntar la verdadera, que es "cinódromo". No decimos "caballódromo", sino "hipódromo", y la misma regla han de seguir todas las voces semejantes [...]. El lugar destinado a carreras de perros es, por consiguiente, el "cinódromo". (La Época, Madrid, 12 de abril de 1928, p. [1b]; HDBN) $)^{15}$.

Ibíd. 26 July 9/4 Something of a novelty has been added to Manchester's odd collection of diversions by the opening of the new greyhound racing track» (OED Suppl.).

15 Unos años más tarde, cuando ya nadie utilizaba la palabra perródromo, el filólogo Avelino Herrero Mayor también censurará su empleo en sus Apuntaciones lexicográficas y gramaticales 
Nótese que el autor indica que "la palabra pudiera divulgarse en los países de lengua española", lo que permite inferir que en ese momento, en abril de 1928, el español no se había decantado todavía por uno de los diversos nombres a los que atenderemos inmediatamente. Araujo se inclinaba decididamente por la utilización de cinódromo, aunque era consciente - y he aquí otra de las cuatro palabras que entran en liza - de que canódromo, que ya tenía algún empleo en la época, sería más transparente para los hablantes. ¿Qué argumentos aduce para sustentar su elección? Habla de tres motivos: uno fonético, otro basado en la necesidad denominativa y, por último, un tercero atinente a cuestiones morfológico-etimológicas. Este último motivo es el que parece tener más peso para Araujo:

(11) [1928] ¿Por qué no canódromo? El "can” latino se conoce más que el "kynos" griego, y las gentes entenderían mejor el vocablo. Pero no hay razón ni costumbre de aliar una voz latina con otra griega. Así, decimos "hidrómetro" y no "acuámetro", "hipódromo" y no "equódromo", "hidroterapia" en vez de "acuaterapia", "odontólogo" y no "denstólogo", "ginecología" y no "muliercología". No hay motivo para que "cinódromo" sea una excepción (Ibíd.).

Termina su escrito solicitando la inclusión de cinódromo en el diccionario académico, lo que nunca llegó a suceder ${ }^{16}$. En cambio, sí se recogió la palabra canódromo — un tanto tarde hay que decir en relación con su uso (\$ 3.4) — en la edición de 1970 del Diccionario de la lengua española: «canódromo. (Del

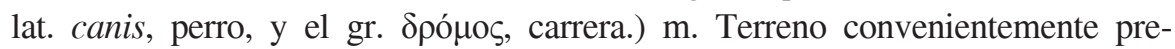
parado para las carreras de galgos». Dos años y medio después del artículo de Araujo, para algunos todavía seguía vivo el debate sobre cómo llamar a las pistas de carreras, como testimonia el diario de Toledo El Castellano: "Las carreras de galgos, en campo abierto o cerrado, están ahora sobre el plano de la moda. España entera es un inmenso Stadium cinódromo, canódromo o galgódromo" (26 de noviembre de 1930, p. 3b; BVCLM).

Cuando a finales de 1931 las carreras de galgos llegaban a Valencia, un tal Almela y Vives, además de hablar del éxito del espectáculo, se detiene en la "grave cuestión filológica" de qué palabra elegir para nombrar las pistas de carreras:

(1947: 218): “¿Quién duda que entre can y perro hay identidad? Lo mismo que entre borracho y ebrio, cabe la homología; pero nadie dirá «fulano es un cínico» con ánimo de llamarlo «perro»... Y, por consiguiente, no se dirá «perródromo» por pista en donde corren los canes...".

16 "La Real Academia Española debe incluir en la edición próxima de su diccionario la palabra «cinódromo», que por lo eufónica, bien formada y necesaria para la vida moderna pide allí el lugar que le corresponde por derecho propio" (Ibíd.). Al día siguiente de la publicación del artículo anterior, un columnista del diario $L a$ Voz escribía otro llamado "Una palabra más", en el que hace un "comentario eutrapélico" de aquel texto y termina irónicamente: "¡Como que yo no sé quién ha podido vivir hasta ahora sin decir cinódromo!" (La Voz, 13 de abril de 1928, p. 1g; HDBN). 
(12) [1931] En él [el asunto de las carreras de galgos] va envuelta una grave cuestión filológica. ¿Cómo llamar al sitio donde corren los galgos? Hay quien lisa y llanamente dice "galgódromo" (mezcla de castellano y de griego). Otros se deciden por esta forma: "canódromo" (mezcla de latín y de griego). Y no falta quien emplea la palabra "cinódromo", que a primera vista resulta bastante pedantesca, pero que tiene la ventaja de su pureza. ¿Cuál de las tres elegir? Dejemos la pregunta en el aire. Intentar resolverla sería salirse plenamente de la frivolidad... ("Crónicas valencianas", La Voz, 26 de diciembre de 1931, p. 4b; HDBN).

Del mismo modo que había sucedido en el diario El Castellano, Almela y Vives habla de las denominaciones canódromo, cinódromo y galgódromo, aunque, como queda dicho, había habido un cuarto contendiente léxico, el sustantivo perródromo. ¿Quiere esto decir que a finales de 1931 esta última voz había dejado de ser una opción posible? Comenzaremos, precisamente, por perródromo.

\subsection{Perródromo}

Debe confesarse, en primer lugar, que el uso que tuvo esta palabra fue realmente escaso, y se limitó casi de manera exclusiva al periodo inicial en el que comenzaba a hablarse en España de las carreras de perros que en 1927 se celebraban en Inglaterra. En los textos que se citan a continuación se menciona el éxito del nuevo deporte - adviértase el resalte tipográfico en 13, que denota el carácter neológico de perródromo - y se subrayan, en 14 y 15, los pingües beneficios que proporcionan las carreras de galgos al estado británico.

(13) [1927] El deporte de las carreras de galgos aumenta considerablemente su boga en Inglaterra. La persecución de la liebre "eléctrica" por los galgos galopadores da lugar a carreras que al parecer proporcionan una emoción inédita a los "sportsmen". Alentados por el éxito, se han creado nuevos "perródromos". (Diario madrileño La Nación, 11 de agosto de 1927, p. 5d; HDBN).

(14) [1927] LONDRES 18.- Se calcula que la moda de las carreras de galgos produce actualmente al Tesoro unas 10.000 libras por semana. En efecto, el promedio semanal de entradas en los perródromos es de unas 410.000 personas, que deben pagar el impuesto sobre espectáculos públicos y, además, una contribución de 2 por 100 sobre las apuestas. (La Nación, 19 de septiembre de 1927, p. 1 ; ; la misma noticia en El Siglo Futuro, el mismo día, p. $3 d$; HDBN).

(15) [1927] En Inglaterra la moda de las carreras de galgos está haciendo un furor loco y los perródromos se ven a diario atestados de público. [...] ¿Cabe mayor desenfreno en los deportes? Porque presupongamos toda la intensidad de las aficiones, pero, vamos, entusiasmarse viendo correr una partida de perros y jugarse el dinero en apuestas sobre qué galgo llegará antes es el colmo de los deportes simplistas. Comprendemos el provecho de estas carreras para los empresarios de los perródromos, pero no nos 
explicamos esa afición tan desmedida de los ingleses, que hacen subir a la cifra de 410.000 personas. (Nuevo Día. Diario de la Provincia de Cáceres, 20 de septiembre de 1927, p. 1c; BVPH).

Como se ha dicho, el espectáculo, a pesar de las críticas y el rechazo iniciales, llegó a España en abril de 1930. A estas alturas la palabra perródromo había quedado totalmente fuera de la pugna léxica que estaban librando otros términos; sin embargo, aún podemos encontrar algún texto en que se documenta aquella palabra, un texto jocoso en el que resuena claramente la ironía. Parece, en consecuencia, que la utilización de perródromo - en unas fechas en que ya otras palabras comenzaban a abrirse paso - responde a una voluntad meramente humorística.

(16) [1931] ¡A ver si se terminan pronto las obras de la pista, hombre, que estamos muy tristes! Llevamos ya varias semanas sin que funciones la "rata mecánica" del Stadium [alusión al artilugio que, al simular una liebre, es perseguido por los perros] y esto no puede ser. Figúrense ustedes que teníamos carreras los lunes. Y los miércoles. Y los sábados. Y siete carreras cada día. Y en cada carrera ocho o diez perritos. Echen ustedes la cuenta. Un verdadero encanto. Esperamos que se vuelva a abrir pronto el perródromo. (Gracia y Justicia, 5 de septiembre de 1931, p. $6 b$; HDBN $)^{17}$.

Sin relación alguna con el limitado uso de perródromo que acaba de describirse, encontramos la misma palabra, desde 2015, en una página electrónica que anuncia un parque en Medellín (Colombia), si bien ha de indicarse que en esta ocasión no designa una pista de carreras, sino un lugar habilitado para los perros donde sus dueños, si lo desean, pueden estar junto a ellos: "El perródromo María Dos Prazeres es un espacio calmado bajo la sombra de grandes árboles en donde puedes estar con tu mascota mientras lees un buen libro" ${ }^{18}$. Es muy probable que este uso esporádico no sea sino un calco del término portugués (de Brasil) cachorródromo, documentado desde 1987: "Proposta canina / O vereador Frederico Barbosa, do PFL de Porto Alegre, propõs a criação, naquela cidade, de um «cachorródromo» - local exclusivo para passeios de cães" (Folha de S. Paulo, 30 de septiembre de 1987, p. 4b; Folha). La palabra perródromo también se utilizó en 1997 en el diario argentino La Nación:

17 Existen algunos casos aislados de esta voz empleada en pediódicos catalanes de la época: "Al perròdromo del Guinardó [inaugurado en 1934], com diu en Ventura Virgilio, es va congregar una selecta y distinguida concurrencia, como diuen els cronistes de societat. Moltes senyoretes $\mathrm{i}$ moltes senyores chipén. Al menú del banquet hi trobàrem a mancar un tall de liebre mecànica" (Xut! Esport i Cinematografia, 16 de julio de 1934, p. 9b; ARCA); "Sentit en un perródromo - como diu un estimat amic - entre dues xicotes de deixa'm encendre" (Papitu, 14 de agosto de 1935, p. 6a; ARCA); “«PERRÓDROMOS» [título] [...] El Sol de Baix és el perródromo més democràtic" (Papitu, 3 de junio de 1936, p. 13a; ARCA).

18 En línea: <https://telemedellin.tv/parque/planea-tu-visita/\#> (consulta: abril de 2018). 
(17) [1997] Aunque la ordenanza municipal 41.831, de 1987, en su artículo 29 insta a los propietarios de animales a proveerse de escobilla y bolsa de residuos durante los paseos que realicen con sus mascotas en espacios públicos, nadie parece respetarla. La norma, inclusive, nunca fue reglamentada. En la reunión entre vecinos y autoridades comunales, que se realizó en agosto último, se barajaron tres propuestas para acabar con las desagradables situaciones callejeras: la utilización de una palita, el guante plástico y la construcción de caniles en las plazas. Esta última opción fue la que menos adhesiones consiguió, en virtud de que los comúnmente llamados perródromos representan un foco de infección y de transmisión de enfermedades. (La Nación, 7 de octubre de 1997).

Pese a que el texto, como vemos, asegura que tales lugares son "comúnmente llamados perródromos", no parece que tal sustantivo —a juzgar por nuestras indagaciones ${ }^{19}$ — esté muy extendido en el español porteño; cabe la posibilidad, no obstante, de que se trate de un caso de "latencia" del léxico coloquial, el cual no siempre aflora fácilmente en textos escritos. Boyd-Bowman (1997-1998: 58), que conocía tan bien el léxico hispanoamericano, al hablar de los elementos grecolatinos que habían penetrado en el español transatlántico a través de los grandes medios de comunicación, mencionaba precisamente la palabra perródromo, si bien no alude a su valor semántico: "gracias a los medios masivos de comunicación, se van difundiendo y hasta generalizando morfemas cultos tomados del griego y del latín clásicos en el español de América. Esto lo indican numerosas voces seudocientíficas y hasta vulgares como aeronauta, autodestaparse, camaronícola, ecoturismo, electrola, [...] perródromo" ${ }^{20}$.

\subsection{Galgódromo}

La segunda palabra en la que debemos detenernos es galgódromo. Mientras que canódromo, cinódromo y perródromo se habían formado con un

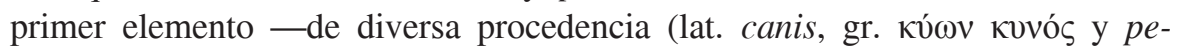
$r_{r}{ }^{21}$ ) - con el que se designa al mamífero doméstico de la familia de los

19 Además de consultar diversos corpus y otras ricas fuentes de información (CORDE, CREA, CNDH, CORPES, CORDIAM, CV, BDH, GL, etc.; $\S 1$ ), se ha recurrido a varias hemerotecas argentinas, como la del diario La Nación o la Hemeroteca Digital Fray Francisco de Paula Castañeda (HPC), y tan solo se ha localizado el texto citado.

${ }^{20}$ El Léxico hispanoamericano de Boyd-Bowman (2007) no recoge la voz perródromo. En España, en los últimos años, se puede encontrar algún empleo aislado de esta voz, como el que a continuación se cita, pero aquí es manifiesto que presenta un claro tono burlón: "El escenario se convierte en canódromo (perródromo, que dijo el otro día, en serio, lo juro, Paz Padilla en «Pa[s]apalabra»)" (Rosa Belmonte, "La pesca en el Mediterráneo", Abc, 4 de agosto de 2008, Madrid, p. 63c).

21 Sobre el «origen incierto» de perro, acúdase a Corominas (1980-1991: IV). Debe indicarse que en el Diccionario crítico etimológico castellano e hispánico no se incluye ninguna de las cuatro denominaciones que estudiamos. 
cánidos, con la voz galgódromo se recurría al hipónimo galgo, al término preciso que designaba a la raza canina concreta que, efectivamente, corría en las pistas. Dejando al margen el procedimiento de creación léxica, lo que sucede en español en este caso es exactamente lo mismo que ocurre en inglés con los términos greyhound track o greyhound racetrack en relación con dog track o dog-racing track. Pues bien, la voz galgódromo —a diferencia de perródromo, cuyo empleo, como acaba de mostrarse, es ocasional- sí que supuso cierta competencia para las voces canódromo y cinódromo. Los primeros testimonios de que disponemos son del año 1927, fecha en la que, como sabemos, el deporte ya se hallaba extendido en Inglaterra. Tales textos hablan de la popularidad creciente de las carreras y de la rápida proliferación de pistas por distintas ciudades británicas, lo que hace que otros deportes consagrados — fundamentalmente el fútbol, aunque también la hípica- teman perder seguidores. En el texto 18 se ofrece un dato interesante: se sugiere la mencionada afición del monarca español a las carreras de galgos. En la cita 20 se expresa la opinión de rechazo a la introducción del deporte en España, basada principalmente en el mantenimiento de la tradición.

(18) [1927] La actualidad de los "g[a]lgódromos" [...] / Londres 16, 7 tarde. (Crónica telegráfica). [...] Comenzaron las eliminatorias para disputarse la copa regalada por S. M. el Rey de España, celebrándose las pruebas en el Galgódromo de White City, en Londres. ( $A b c, 17$ de agosto de 1927, p. 25c).

(19) [1927] Comenzaron a correrse en el estadio de White City, donde se instaló el primer galgódromo, pero, debido al formidable éxito, se han abierto ya más de cuarenta, amenazando invadir poco a poco todos los grandes campos dedicados hasta ahora al fútbol. ( $A b c, 13$ de noviembre de 1927, p. 13a).

(20) [1928] En España, sin galgódromos, como en otros países, por no ser necesario, ya que nuestro campo produce liebres en abundancia que permiten correrlas con galgos, no es necesario utilizar la liebre mecánica, que solo comercialmente tiene justificación. (Revista Cinegética Ilustrada, 66 (1928), p. 20a; HDBN).

A partir de abril de 1930, cuando el deporte fue introducido en España, también se utilizó la voz galgódromo en alusión, principalmente, a la pista de carreras madrileña de Cuatro Caminos, el llamado Stadium Metropolitano (véase la Figura 2). El uso de este sustantivo se mantiene hasta principios de los años treinta — nótese que en algunos casos se resalta tipográficamente bien con comillas, bien con cursiva_-; después, aunque podemos encontrarlo en algunos textos, es bastante raro en la Península: 


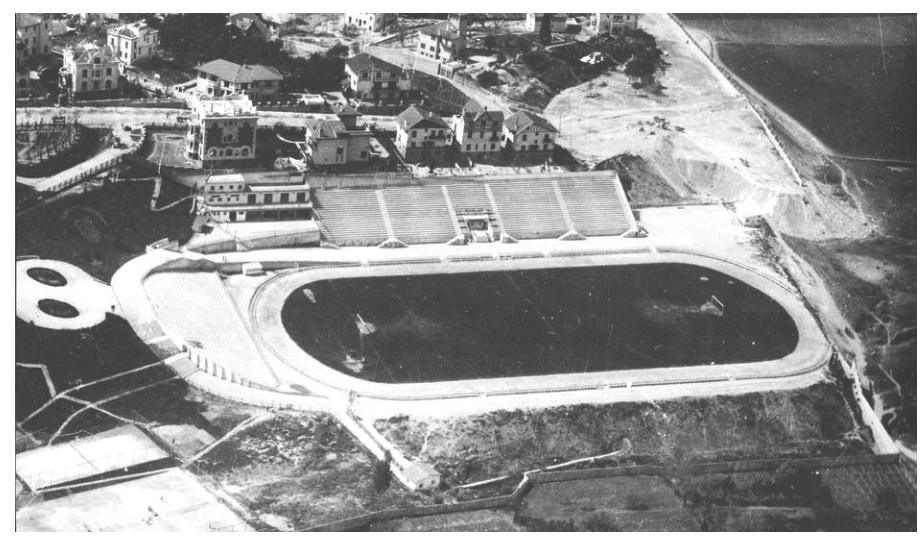

FIGURA 2.-Stadium Metropolitano de Madrid.

(21) [1930] Otra explotación realiza el Stadium, ahora que está condenado a no exhibir matches de fútbol, precisamente por esas otras organizaciones que establecen una competencia. Nos referimos a las carreras de galgos tras liebres mecánicas, que vienen a Madrid después de que han sido en muchos países objeto de predilección de los públicos. El "galgódromo" de los Cuatro Caminos tiene el aval de un grupo de aristócratas que desean popularizar este ejercicio de... sus galgos. (Revista madrileña semanal Crónica, 13 de abril de 1930, p. [22a]; HDBN).

(22) [1930] —Vea estas fotos [son palabras literales del secretario del Club Deportivo Galguero y gerente del Stadium, Joaquín Losada Pinedo], que nos muestran el galgódromo lleno de gente e iluminado, en una sesión nocturna. (Mujeres Españolas, n. ${ }^{\circ}$ 66, 25 de mayo de 1930, p. 22; BVPH; véase la Figura 3).

(23) [1930] CARRERAS DE GALGOS / Anoche celebrose en el galgódromo del Stádium la quinta reunión de verano de carreras de galgos. El éxito de las sesiones anteriores fue aún mayor en la de ayer, pues el público llenó todos los recintos. (La Época, 25 de julio de 1930, p. 2b; HDBN).

(24) [1930] El gran dividendo correspondió esta vez a "Daganzo", que pagó a 23 por uno, lo que, si no constituye el récord del galgódromo, debe acercarse mucho. (La Nación, 21 de agosto de 1930, p. 7c; HDBN).

(25) [1930] La animación no decae. Ayer había un gentío en el galgódromo. (La Nación, 9 de septiembre de 1930, p. 9a; HDBN).

(26) [1930] La oveja delante y la vulpeja detrás corrieron la huerta varias veces, a la manera de los galgódromos. (La Nación, 31 de octubre de 1930, p. 16c; HDBN).

(27) [1930] El Club Galguero ha trasladado a su vez la correspondiente reunión del galgódromo al jueves. (Gran Sport, 18 de noviembre de 1930, p. 1e; $\mathrm{BVPH})$.

(28) [1931] Se están haciendo gestiones entre la directiva del Valencia y la del club Galguero de Madrid, para celebrar carreras de galgos o podencos [...]. De llegarse a un acuerdo, el campo de Mestalla quedaría 
convertido en un galgódromo. (Diario valenciano Las Provincias, 11 de agosto de 1931, p. 15d; BVPH).

(29) [1931] Se celebró ayer en el galgódromo madrileño la X reunión de otoño. (Heraldo de Madrid, 3 de diciembre de 1931, p. 7a; HDBN).

(30) [1932] El campo de Las Corts será pronto galgódromo. (Diario valenciano Las Provincias, 24 de febrero de 1932, p. 16e; BVPH).

(31) [1933] Si otra vez "cuaja" el galgódromo, se habrá perdido para el Stadium el fútbol. (Heraldo de Madrid, 27 de mayo de 1933, p. 8d; HDBN).

Importa señalar que en algunos textos conviven o bien galgódromo y canódromo, o bien cinódromo y canódromo (cfr. también el texto 63). Este hecho, motivado por la variación estilística, nos da cuenta de la vigencia de estas palabras en un periodo determinado, aproximadamente entre 1927 y 1933.

(32) [1930] GALGÓDROMO [título de sección] [...] Así, con esa complacencia de la obra terminada, van al canódromo el duque de Pastrana, conde de Lérida, marqués de Villabrágima, Calín y Martín. ( $\mathrm{La}$ Voz, 7 de julio de 1930, p. 11g; HDBN).

(33) [1931] El Stadium resulta ahora el mejor canódromo del mundo [...] Ningún cinódromo ni hipódromo del mundo puede dar las mismas garantías —absolutas - que [1]a pista madrileña en cuanto a las llegadas. (Heraldo de Madrid, 16 de mayo de 1931, p. 12e; HDBN).

(34) [1931] "Bohemio", en su modesta categoría, es el perro más "intelectual" del canódromo. [...] El excelente ejemplar "Still Sur e" [pie de foto en que se muestra un galgo], de José Luis Gómez, que ayer ganó en el galgódromo madrileño el preciado y disputado trofeo anual "Copa de Verano". (La Voz, 17 de agosto de 1931, p. 11a; HDBN).

(35) [1931] Inaugúrase el Canódromo de Vallejo [título de la noticia] / [...] Es bien posible adquiera arraigo este deporte en nuestra ciudad [Valencia], como ya lo tiene en Madrid y Palma de Mallorca, donde funcionan galgódromos desde hace tiempo. [...] Un modesto aficionado acudía, con un hermoso galgo que alojaba en las perreras del canódromo, para inscribirlo en las próximas carreras a celebrar. (La Correspondencia de Valencia, 7 de diciembre de 1931, p. 6b; BVPH).

(36) [1931] Valencia el día 6 del presente mes abrió el tercer cinódromo español [...]. Los catalanes —el Polo hockey Club por más detallesgestiona[n] la instalación de otro canódromo. (Diario cartagenero República, 29 de diciembre de 1931, p. 2c; AMC).

Recuérdese el texto de Almela y Vives, que citábamos más arriba (12), donde se planteaba "cómo llamar al sitio donde corren los galgos" y se aseguraba, a finales de 1931, que unos decían "lisa y llanamente" galgódromo, otros se decidían por la voz canódromo e incluso había quien utilizaba cinódromo, que, a juicio del autor, resultaba "bastante pedantesca", pese a tener "la ventaja de su pureza". El valioso testimonio de Almela y Vives viene a confirmar lo que nos muestran los datos que estamos presentando: que estas tres voces convivie- 
ron durante los primeros cinco o seis años en que comenzaron a ser utilizadas, aunque dos de ellas dieran cuenta de su pujanza durante este periodo inicial. Se emplea, pues, la palabra galgódromo en España entre los años 1927 y 1933; a partir de entonces su uso es ocasional, como sucede en la cita que se recoge a continuación. Cuando ya no cabía la más mínima duda de la elección léxica que habían hecho los hablantes peninsulares, todavía había quien insistía en que debería haberse llamado galgódromo al circuito destinado a las carreras de perros:

(37) [1984] Para ofrecerles este trabajo sobre el Canódromo Madrileño, sobre las carreras de galgos por dentro (a mí me gustaría más, y hasta creo que sería más exacto y riguroso llamarle galgódromo), he visitado dos veces el recinto de la Vía Carpetana. (Hoja del lunes de Madrid, 9 de abril de 1984, p. 37; BVPH).

A pesar de su observación, Juan Manuel Gozalo, autor del amplio reportaje al que pertenece este texto ("Los galgos, esos grandes desconocidos"), es muy consciente de cuál es la palabra que había desbancado a las demás y llevaba décadas usándose en España; hablamos, desde luego, de canódromo, utilizada más de una cincuentena de veces en este reportaje. Aparte de que, en efecto, son galgos los perros que realizan estas carreras, la preferencia por galgódromo también pudo deberse a otro motivo, y es que, mientras que en España había triunfado la voz canódromo, en México lo había hecho galgódromo, donde esta voz empezó a utilizarse temprano ${ }^{22}$ :

(38) [1929] Las carreras de galgos, distracción de "niñas bien" y desgracia de algunos cientos de individuos de nuestra clase media, es otra explotación que debe prohibirse cuanto antes. El llamado "galgódromo", para cuya construcción fue necesaria una gruesa suma que, invertida en los pródigos campos de Morelos, hubiera logrado contener una buena parte de nuestros emigrantes, es también un espectáculo que repugna por su inmoralidad. (Revista Crisol, vol. 2, 1 de julio de 1929, p. 78; GL).

(39) [1930] El señor Presidente de la República asistió hoy a los festejos organizados por la Colonia Americana y que se efectuaron en el galgódromo. (Guadalajara, El Informador. Diario Independiente, 5 de julio de 1930, p. $6 e$; HNDM).

(40) [1941] CONSIDERANDO que el establecimiento de un Galgódromo en esta capital de la República acarrearía notorios beneficios [...]. (Periódico oficial. Órgano del Gobierno del Territorio Norte de la Baja California, 20 de noviembre de 1941, p. 9b; HNDM).

(41) [1977] De manera, hip, que ser médico, siempre lo he dicho, es mejor que ser ingeniero, contador público, licenciado en ciencias de la comuni-

22 Dos de los textos que se citan proceden de la Hemeroteca Nacional Digital de México. El CORDE y el CORDIAM no recogen textos en los que se documente el sustantivo galgódromo. En cambio, el CNDH recupera seis textos con la voz galgódromo (periodo: 1977-1996), todos ellos pertenecientes al español de México, y CORPES ofrece siete textos del mismo país para el periodo 2001-2014. Por su parte, GL recupera numerosos textos mexicanos que contienen dicha voz publicados a partir de 1950. 
cación, operador de las liebres mecánicas de los galgódromos o incluso mejor que ser experto en coprolitos... (Fernando del Paso, Palinuro de México, Madrid, Alfaguara, 1977, p. 80; GL).

(42) [2007] Sección III / De los galgódromos / Artículo 53. Galgódromo es el escenario en el que de manera permanente o temporal se realizan carreras de galgos. Comprende la pista, gradas y todas las demás instalaciones que, directa o indirectamente, integran la unidad física mediante la cual se proporcionan los elementos muebles e inmuebles para la preparación, desarrollo y evaluación de las carreras, así como las áreas donde se realicen actividades complementarias del espectáculo. (Suprema Corte de Justicia de la Nación, Semanario Judicial de la Federación y su Gaceta, t. XXVI, septiembre de 2007, p. 2180; GL).

Debe indicarse, no obstante, que en México también se ha utilizado la palabra canódromo, si bien es mucho más frecuente galgódromo, voz considerada oficial, como muestra su presencia en distintos textos gubernamentales (42). Un dato elocuente bastará para mostrar la preferencia por galgódromo en este país: la búsqueda de esta voz en la Hemeroteca Nacional Digital de México $^{23}$ —en la que se pueden localizar voces en los textos de cerca de 900 publicaciones periódicas mexicanas (39 y 40 proceden de esta fuente) - recupera 386 textos, comprendidos entre 1929 y 2006. En cambio, la búsqueda del sustantivo canódromo ofrece tan solo 44 textos, desde 1929 hasta 1999. Por otro lado, son varias las obras lexicográficas que codifican la voz galgódromo como propia de México. El Diccionario de americanismos (2010) de la ASALE así lo marca y el Diccionario de mexicanismos (2010) de la Academia Mexicana de la Lengua también lo recoge: "M. Canódromo"24.

\subsection{Cinódromo}

El tercer sinónimo de que dispuso el español para designar el lugar donde se realizan carreras de perros es cinódromo. Además de la coherencia morfológica

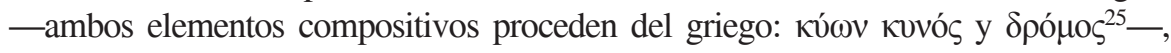

23 HNDM (consulta: abril de 2018).

24 Asimismo, el Compact Oxford Spanish Dictionary, dirigido por Rollin, Styles Carvajal y Horwood (2013: 197), también incluye la palabra galgódromo como propia de México: "galgódromo $m$ (Méx) dog track".

25 Pharies (2002: 172) —que sobre '-dromo indica que es un «Elemento final que refleja el elemento de compuestos griego $-\delta \rho \mu_{\circ} \varsigma$, también átono, derivado, junto con $\delta \rho{ }^{\prime} \mu \varsigma$ 'carrera', de $\delta \rho \alpha \mu \tilde{\omega}$ 'correr'»— solo recoge de los cuatro compuestos que nos ocupan la «formación híbrida» canódromo. Lo mismo sucede en la obra de Rainer Spanische Wortbildungslehre: «-ódromo: Bildungen mit dem Suffix -ódromo bezeichnen Anlagen, an denen die in der Basis genannten Vehikel bzw. Tiere Rennen austragen: autódromo, canódromo, hipódromo, velódromo. Die Basen sind teilweise gebundene Stämme» (1993: 624). En relación con las «bases compositivas cultas», 
es cierto que la raíz prefija cino- está presente en español en otras voces, o bien

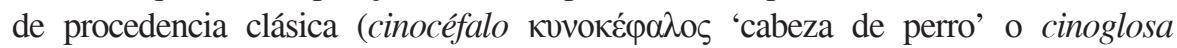

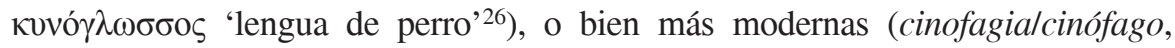
cinofilialcinófilo, cinofobialcinófobo, cinoformo, cinografía, cinologíalcinológico, etc.). Asimismo, la voz cinódromo contaba a su favor con algo no menos importante: era la palabra que habían elegido otros países europeos para nombrar las pistas de carreras de galgos. En septiembre de 1927 el periódico parisino Le Journal anunciaba la inauguración del "primer cinódromo francés" (cfr. texto 53) ${ }^{27}$ :

(43) [1927] SPORT CANIN / Le premier " cynodrome » français. — / C'est dimanche prochain, dans le parc de Lys-Chantilly, que sera inauguré le premier champ de courses de lévriers en France. Soixante greyhounds prendront part aux épreuves que feront disputer le Lévrier Club de France et le Lévrier Club de Normandie. (Le Journal, 23 de septiembre de 1927, p. 3g; Gallica) ${ }^{28}$.

(44) [1927] C'est à Chantilly, ville sportive, que sera inauguré, aujourd'hui, le premier champ de courses de lévriers, dans le cadre merveilleux du parc

la NGLE ofrece la siguiente información morfológica: “-́dromo 'estadio' (del gr. -́dromos, de drómos 'carrera"” (2009: § 11-10a), y, algo más adelante, menciona, como los dos anteriores autores, el sustantivo canódromo: "A pesar de que drómos significa 'carrera' en griego, los compuestos que se forman con esta base culta no solo designan estadios y otros recintos en los que se celebran tales competencias (canódromo, hipódromo, velódromo), sino otros lugares abiertos en los que no tienen lugar (aeródromo, rocódromo)" (2009: § 11-10j).

26 Aunque no comienzan por el formante cino-, también proceden de la misma voz griega, naturalmente, palabras como cínico o cinismo.

27 Debemos señalar que la palabra cynodrome se documenta en francés en 1900, pero, tal y como muestra el siguiente texto, no se trata de las carreras de perros de las que hablamos; ni son galgos ni corren tras la conocida liebre mecánica: "CONCOURS DE CHIENS DE BERGER / Le 1' juillet prochain, les Parisiens pourront assister à un spectacle assez original, attendu surtout qu'il se produira aux portes mêmes de Paris. Ce jour-là, l'hippodrome de Levallois-Perret se transformera en cynodrome; le Club français du chien de berger, à l'occasion de l'Exposition, abandonne les champs et les prairies de la Brie et donnera sur cet hippodrome, mis gracieusement à sa disposition par la Société d'encouragement, son grand concours annuel. Les chiens de berger remplaceront donc les demisang. Ils se réuniront sur la pelouse, tenus en laisse par leurs conducteurs; puis, soit par couples, soit isolément, ils auront à faire suivre la piste à un lot de moutons, les obligeant à franchir correctement les obstacles, fossés, banquettes, haies, etc., et à traverser sans bousculade le défilé du passage rétréci. De son côté, le personnel du marché de la Villette présentera l'élite de ses chiens, si remarquablement dressés". (Le Petit Troyen. Journal Quotidien de la Démocratique de l'Est, 23 de mayo de

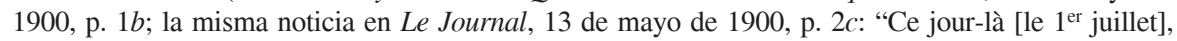
en effet l'hippodrome de Levallois sera changé en cynodrome"; Gallica).

${ }^{28}$ El Trésor de la langue française (1971-1994: VI) ofrece la siguiente información: “cynodro-

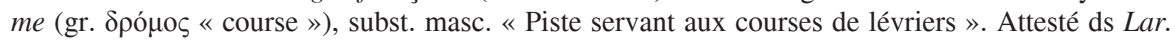
$20^{e}$-Lar. Lang. fr.". Como vemos, la primera documentación que ofrece esta obra es el Larousse $d u X X^{e}$ siècle en six volumes (París, Larousse, 1928-1933), dirigido por Paul Augé. La otra obra que cita el Trésor es el Grand Larousse de la langue française en sept volumes, bajo la dirección de Louis Guilbert, René Lagane y Georges Niobey (París, Larousse, 1971-1978). Por su parte, el Dictionnaire alphabétique et analogique de la langue française marca la voz cynodrome como neologismo: "n. m. (Néol.; gr. kyôn-kynos, chien, et dromos, course). Piste aménagée pour les courses de lévriers" (Robert, 1966-1978: s. v.). 
de Lys-Chantilly. Ce « cynodrome »- avec un $c$, puisque nous écrivons cynique et non kynique — va permettre de juger, mieux qu'on n'a pu le faire jusqu'à présent, l'intérêt que présente le spectacle de ces épreuves disputées avec acharnement par d'admirables chiens, indiscutablement destinés par leurs formes et leurs aptitudes à la course ${ }^{29}$. (Le Journal, 25 de septiembre de 1927, p. 1f; Gallica).

La puntualización (orto)gráfica del segundo texto denuncia la existencia, junto a la forma cynodrome, con $c$, de la variante gráfica kynodrome, con $k$. En efecto, diversos periódicos — sobre todo, de los años veinte- contenían la palabra con esta última grafía, índice de la inestabilidad gráfica propia de algunos neologismos, fundamentalmente durante sus primeros años de vida; prueba también de esta inestabilidad es la utilización de comillas o subrayado. En algunos casos se emplea la voz kynodrome en referencia a otros países, pero a partir de 1927 se utiliza para nombrar los cinódromos galos:

(45) [1919] Le Greyhound Club de Belgique, qui a donné de nombreuses réunions pedant l'occupation, au Kynodrome du Cinquantenaire continue sa série d'épreuves sur l'Hippodrome de Laeken. (L'Éleveur. Journal Hebdomadaire Illustré, 25 de mayo de 1919, p. 65a; Gallica) ${ }^{30}$.

(46) [1924] Malgré un vent violent, de nombreux sportsmen s'étaient rendus au «Kynodrome » de la Californie pour assister à la première journée des courses de lévriers. (Le Figaro, 3 de febrero de 1924, p. $2 d$; Gallica).

(47) [1924] Mercredi dernier, de nombreux sportsmen s'étaient donné rendezvous au « Kynodrome » de l'aviation, à la Californie, pour assister à la première course de lévriers. [...] La réunion d'aujourd'hui, que attirera certainement un nombreux public sur notre « Kynodrome », commencera à 14 h. 30. (L'Éclaireur du dimanche et «La Vie Pratique, Courrier de Etrangers», 3 de febrero de 1924, p. 21b-c; Gallica).

(48) [1926] Le chiens, fort bien! Et les hommes?... Les lévriers sont de magnifiques animaux et les courses de lévriers constituent un admirable spectacle. Le Lévrier Club de France organise le 12 décembre, au Palais des Expositions, la Journée internationale du Lévrier. Cette journée se terminera par

29 "PARIS, Jan. 21. - An attempt is now being made to introduce greyround coursing into France. Although this sport quickly captured England after being brought to the attention of the fashionable public by an American, Charles Munn, the present is the first considerable effort to introduce this sport across the Channel". (The New York Times, 22 de enero de 1928, p. 36h).

${ }^{30}$ Las carreras de galgos desarrolladas en Bélgica durante la Primera Guerra Mundial no contaban aún con el mecanismo de la liebre mecánica: "Fue durante la guerra, en Bruselas, donde se celebraron las primeras carreras; los teatros estaban cerrados; los caballos de carrera no existían ya..., y la ocupación alemana no permitía ninguna reunión pública. Toleraba, sin embargo, estos espectáculos que lograron en poco tiempo auge tal que cinco cinódromos funcionaban al mismo tiempo alrededor de la capital belga. [...] En Bélgica y en Francia, los competidores [los perros], colocados en la línea de partida, se les da suelta en el momento en que el «starter» da la señal, lanzándose entonces aquellos hacia el punto de llegada, desde donde les llaman sus propietarios o educadores" (Revista Cinegética Ilustrada, n. ${ }^{\circ}$ 53, noviembre de 1927, p. 24a- $b$; HDBN). 
des courses disputées sur un « kinodrome » couvert. Cela est fort bien. Cela sera fort joli. [...] Ainsi, nous allons avoir, à Paris, un « kinodrome » couvert. (L'Intransigeant, 6 de diciembre de 1926, p. 4b; Gallica).

(49) [1927] De grâce, nous écrit M. Mayr, n'inventons pas le mot kynodrome, sinon nous serions obligés bientôt de parler de kynisme, de kinéma, de kycles, de kynoképhale, de kétakés... Juste observation; allons donc au cynodrome. (L'Intransigeant, 29 de septiembre de 1927, p. $2 d$; Gallica).

El italiano, por su parte, optó también por la misma formación, aquella que unía dos elementos compositivos griegos. A finales de los años veinte comienza a utilizarse en Italia la voz cinodromo: 'L'Inghilterra conta già un numero rispetabile di cinodromi. Parigi si prepara ad imitarla. [...]" (La Stampa, 5 de marzo de 1928, p. $3 d)^{31}$. El caso del catalán es llamativo, pues la palabra que triunfó — probablemente por influencia del canódromo español— fue canòdrom (cfr. textos 93-97), que es la que figura en varios diccionarios catalanes y en centenares de textos de esta lengua (cfr., por ejemplo, ARCA); ahora bien, también se utilizó la voz cinòdrom, sobre todo a partir de los años setenta:

(50) [1976] Els premis foren atorgats al neorealisme expressiu i biomecànic del cinòdrom Mer[i]diana, d'Antoni Bonet i Josep Puig, i al Departament d'Electrònica de la Caixa de Pensions, de Casas Puig. (Avui, 25 de diciembre de 1976, p. 20b; $\mathrm{AMG}^{32}$ ).

Al igual que canòdrom, la voz cinòdrom se registra en distintos repertorios lexicográficos del catalán, como la Gran enciclopèdia catalana (Carreras i Martín, 1981): "cinòdrom $m$ ESPORT Conjunt de pista (de forma el-lipsoïdal) i instal-lacions auxiliars destinades a la celebració de curses de llebres, amb el correspondent departament per al tràmit de les juguesques". En el Diccionari de la llengua catalana (1995), del Institut d'Estudis Catalans, se recoge el siguiente artículo: "cino- Forma prefixada del mot gr. kýon kynós, 'gos'. Ex.: cinomorf, cinòdrom”. Alcover y Moll (1930-1962) no incluyen en el Diccionari catalàvalencià-balear ni canòdrom ni cinòdrom; téngase en cuenta que el volumen II (arr-car) se publicó en 1935, cuando canòdrom comenzaba a tener algún uso en catalán (\$ 3.4); y el volumen III (cas-cuy) vio la luz en 1950, cuando cinòdrom no tenía circulación en esta lengua ${ }^{33}$.

Así como el francés sí pudo influir en que empezara a utilizarse en España la palabra cinódromo a partir de 1925, el italiano no parece que tuviera influencia

31 El Grande dizionario della lingua italiana, de Battaglia, recoge la voz, pero no ofrece testimonio alguno de ella: "Cinòdromo, sm. Luogo ove si effettuano le corse di cani. = Voce dotta,

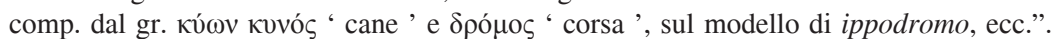

32 El AMG recupera 276 textos comprendidos en el periodo 1976-1997. Una gran parte de tales textos se refiere al «Cinòdrom Meridiana» (cfr. texto 95).

$33 \mathrm{El}$ Diccionari etimològic i complementari de la llengua catalana no recoge ni canòdrom ni cinòdrom (cfr. Corominas, 1991-1995: s. v. ca 'gos' y cínic). 
alguna en español, puesto que los primeros testimonios del cinodromo italiano son posteriores a los españoles. En cuanto al catalán cinòdrom, no supuso ningún efecto en el español por cuestiones cronológicas obvias. Aunque documentamos la voz cinódromo en castellano en 1925, su uso empieza a ser notable a partir de 1927, y continúa utilizándose hasta 1935. Como sucede con otras voces sinónimas ya tratadas, los primeros testimonios que tenemos de cinódromo aluden a pistas extranjeras, de La Habana (51), Inglaterra (52 y 54) o Francia (53):

(51) [1925] Habana.-Entre las medidas que ha adoptado el nuevo gobierno cubano figuran las siguientes: Pro[h]ibiendo el juego. —Antes se jugaba en los frontones, carreras de caballos, cinódromo [...]. El señor Cuervo [...] se suicidó a causa de haber perdido en la [texto ilegible] del Cinódromo 400.000 pesos, al dar quiebra el negocio por haberse prohibido el juego. (Diario santacrucero La Prensa, 18 de julio de 1925, p. 2b; BVPH).

(52) [1927] El público que va a los partidos de fútbol es muy distinto del que asiste a las carreras de galgos: el primero está compuesto de aficionados que acuden atraídos por el deseo de presenciar su juego predilecto, y el segundo está formado por personas que van al cinódromo con el propósito de jugarse unos chelines. [...] Suprímanse las apuestas y se habrá puesto fin a las carreras. (Blanco y Negro, 20 de noviembre de 1927, p. [64b]; Abc).

(53) [1927] El 25 del pasado septiembre se inauguró el primer campo de carreras en el magnífico parque Lys-Chantilly. Este cinódromo va a permitir lo que hasta hoy no ha sido posible: formarse un juicio exacto respecto del interés que presenta el espectáculo de estas pruebas disputadas con encarnizamiento por admirables perros destinados por sus formas y aptitudes para la carrera. (Revista Cinegética Ilustrada, n. ${ }^{\circ}$ 53, noviembre de 1927, p. 24a; HDBN).

(54) [1928] Han tenido lugar recientemente las carreras de galgos sobre la amplia pista o cinódromo construido en Mánchester. (Madrid, Abc, 29 de mayo de 1928, p. 16b).

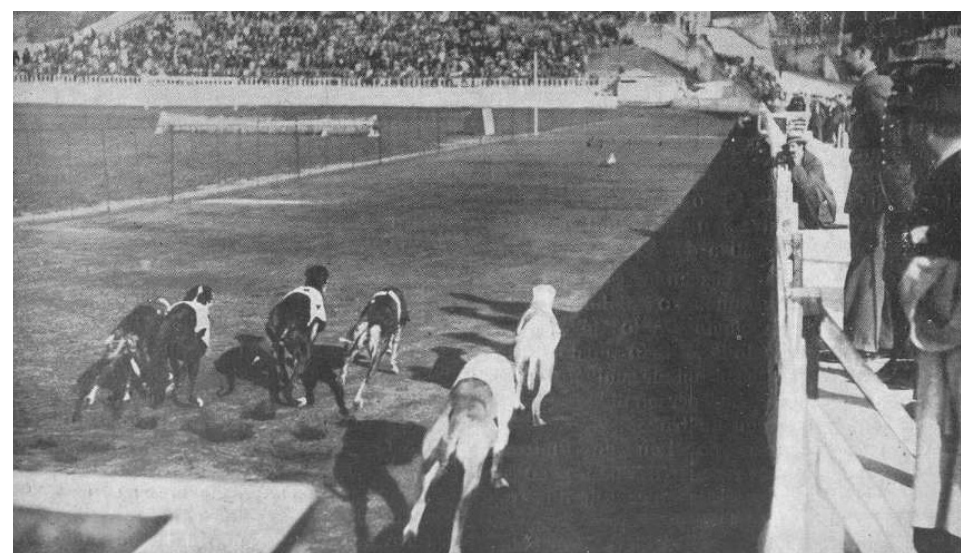

FigURA 3.-Mujeres Españolas, n. ${ }^{\circ}$ 66, 25 de mayo de 1930, p. 21. 
Recuérdese ahora lo que afirmaba en abril de 1928 Luis Araujo Costa en su artículo "Cinódromo y no perródromo" (10 y 11), donde defendía con convicción la primera palabra. Pues bien, desde el año 1930 se emplea la voz cinódromo para referirse principalmente a pistas de carreras españolas, sobre todo en alusión al Stadium Metropolitano.

(55) [1930] CARRERAS DE GALGOS EN EL STADIUM / El Club Deportivo Galguero celebró en el cinódromo del estadio su décima reunión de la temporada. (Heraldo de Madrid, 16 de junio de 1930, p. 9d; HDBN).

(56) [1930] Un público numeroso presenció la reunión de anoche en el cinódromo del estadio Metropolitano. (La Libertad, 14 de agosto de 1930, p. $10 a$; HDBN).

(57) [1930] A pesar de que el tiempo se presentó indeciso, la creciente afición al nuevo deporte no desertó de su periódica asistencia al cinódromo del Stadium Metropolitano. (Gran Sport, 19 de octubre de 1930, p. 2e; BVPH).

(58) [1930] En el cinódromo, Chula II ganó la carrera más importante. (Diario madrileño Ahora, 16 de diciembre de 1930, p. 33d; HDBN).

(59) [1931] El galgo es un perro aristócrata: lo poseen los labradores acomodados, los curas [...]; ahora lo poseen, además, las muchachas deportistas, los señoritos ricos y una especie nueva de "croupiers" que los dedican a correr en los "cinódromos" como caballos de carreras. (Diario santanderino El Cantábrico, 2 de enero de 1931, p. 1a; BVPH).

(60) [1931] El retraso de media hora de las indicadas será motivo para no permitir el acceso al cinódromo. (Abc, 11 de febrero de 1931, p. 51b).

(61) [1931] Una de estas carreras será para los de cuarta categoría y la otra es el match Cancionera-Lizán, tan esperado por los asiduos del cinódromo madrileño. (Abc, 10 de junio de 1931, p. 45b).

(62) [1931] La misérrima vida que el atletismo lleva en España tiene una clara concreción en Madrid. Aquí, donde los galgos tienen su cinódromo, y su hipódromo los caballos y las motos acrobáticas su pista negra y magnífica, los hombres carecen del lugar adecuado para el desarrollo de sus aficiones atléticas. (Revista semanal Crónica, 2 de agosto de 1931, p. [27b]; HDBN).

(63) [1931] Justo es reconocer que hasta hace poco tiempo la afición estaba circunscrita al canódromo madrileño dentro de la península y al de Palma en las Baleares. Valencia el día 6 del presente mes abrió el tercer cinódromo español. (Diario alicantino El Luchador, 29 de diciembre de 1931, p. 4a; BVPH).

(64) [1932] Este nuevo triunfo confirma la creencia general de que es uno de los mejores "staryers" del cinódromo madrileño. (El Sol, 13 de marzo de 1932, p. 9d; HDBN).

(65) [1932] GALGOS / EN EL CINÓDROMO METROPOLITANO ( $\mathrm{La} \mathrm{Voz,}$ 21 de marzo de 1932, p. 11c; HDBN).

(66) [1932] Nosotros preferiríamos que la igualdad se hiciera a base del estado actual de las reuniones del cinódromo. ( $\mathrm{La}$ Voz, 13 de junio de 1932, p. 10d; HDBN).

(67) [1933] GALGOS / OTRA VEZ EL CINÓDROMO. ( $\mathrm{La} \mathrm{Voz,} 29$ de mayo de 1933, p. 10f; HDBN). 
(68) [1934] El domingo día 27 de este mes será la reapertura del cinódromo madrileño. (La Libertad, 19 de mayo de 1934, p. 9b; HDBN).

(69) [1934] Dentro de poco contaremos con un nuevo cinódromo. Se trata del de Cartagena, que se inaugurará el día 11 del presente mes. (La Época, 3 de agosto de 1934, p. 4c; HDBN).

(70) [1934] La próxima reunión en el cinódromo del Stadium Metropolitano se celebrará mañana martes, día 14. (Luz. Diario de la República, 13 de agosto de 1934, p. 14a; HDBN).

(71) [1934] En el cinódromo valenciano de Vallejo una prueba de galgos tuvo un desenlace trágico e inesperado. (Blanco y Negro, 26 de agosto de 1934, p. 32a; $A b c)$.

(72) [1935] El programa se puede considerar como extraordinario, el más importante de los que se han dado hasta ahora en el cinódromo. ( $\mathrm{La} \mathrm{Na}$ ción, 15 de febrero de 1935, p. 14c; HDBN).

(73) [1935] En la jornada última en el cinódromo del Stádium los resultados fueron [...]. ( $L a$ Voz, 28 de febrero de 1935, p. 10a; HDBN).

(74) [1935] Ayer se han formalizado las inscripciones para la próxima reunión del cinódromo. (Diario madrileño La Tierra, 9 de mayo de 1935, p. 4b; HDBN).

(75) [1935] El Club Deportivo Galguero ha confeccionado para mañana domingo, a las cuatro de la tarde, un interesante programa, en el que intervendrán los mejores galgos de este cinódromo, sobre la distancia de 500 yardas. (El Siglo Futuro, 12 de octubre de 1935, p. 20c; HDBN).

A partir de mediados de los años treinta es raro el uso de cinódromo en España. Según los testimonios considerados, dicha voz se utilizó en nuestro país fundamentalmente entre los años 1927 y 1935, si bien a comienzos de los años treinta los hablantes comenzaban a decantarse por la palabra canódromo. Pese a que cinódromo fuera una palabra obsolescente en 1935, en algunos medios, incluso oficiales, aún resonaba, de manera muy débil, la agonizante voz. En la legislación sobre las carreras de galgos se trató de establecer el nombre que debían tener las pistas, tal y como se observa en el Reglamento de carreras de galgos con apuestas mutuas, aprobado por el Ministerio de la Gobernación el 28 de marzo de 1935. En el capítulo II, llamado "Del canódromo", se dice: "El campo en donde se celebren las carreras de galgos se denominará «canódromo» o «cinódromo»" (Gaceta de Madrid, 29 de marzo de 1935, p. 2486b; GM). Además de concederle prioridad a la voz canódromo desde la propia denominación del artículo, también se la otorgaba de manera manifiesta el propio texto del Reglamento al utililzar esta voz en veintisiete ocasiones, mientras que cinódromo solo aparecía en el fragmento citado. En esta época, según lo que parece sugerir la documentación manejada para este estudio, era clara la preferencia de los hablantes peninsulares. Cinco años antes de la publicación de este reglamento, el Club Deportivo Galguero había establecido un "Código de carreras", con 18 capítulos y 95 artículos, que se publicó por entregas en el Heraldo Deportivo entre el 15 de abril y el 15 de octubre de 1930. En este código se empleaba 
canódromo en cuatro ocasiones, lo que acaso también debió de contribuir a que esta voz fuera ganando terreno poco a poco a sus rivales léxicos ${ }^{34}$.

Aún debemos referir un episodio de la voz cinódromo, que nos lleva a tratar su arraigo en un país hispanoamericano; de hecho, en este país comienza a utilizarse muy temprano dicha voz. Hablamos de Cuba. Aunque disponemos de testimonios desde 1926, es muy posible que la palabra cinódromo circulara algún año antes, puesto que - de acuerdo con los textos 51 y 78- Cuba tuvo una pista habilitada para las carreras de perros "en la calle 33 en el Vedado", al menos, hasta 1925, año en el que fue cerrada como consecuencia de la prohibición del juego decretada por el gobierno dictatorial del general Gerardo Machado. La existencia de este primer cinódromo cubano es un hito de suma importancia para la historia de este deporte, pues recuérdese, por un lado, que las carreras de galgos no llegaron a Inglaterra sino en 1926 y, por otro, que en España no se dispondría de un canódromo hasta abril de 1930. Los primeros textos cubanos que conocemos hablan de los cinódromos de otros países:

(76) [1926] El Coronel Ruppert, dueño de los Yankees, Dave Bancroft, manager del Boston, y Walter Hagen, el famoso golfista, han cogido tal fiebre por los perros que están planeando la manera de poner un Cinódromo en St. Petersburg. (Diario de la Marina, 23 de marzo de 1926, p. 21h; BVPH).

(77) [1927] Las carreras de perros en el cinódromo de Hillsborough también fueron reanudadas anoche. (Diario de la Marina, 17 de enero de 1927, p. $17 g$; BVPH).

A partir de marzo de 1927, en el afamado Diario de la Marina, se recogen varias noticias en las que se comunica que se ha solicitado una autorización para construir un nuevo cinódromo, ahora en el municipio habanero de Marianao.

(78) [1927] CINÓDROMO / [...] En el Registro General del Municipio fue entregado ayer por orden del señor Manuel Pereira, ex Alcalde interino de la Habana, el expediente que tenía en su poder para estudio y en que se solicitaba autorización de la Alcaldía para establecer en el término municipal un Cinódromo, en iguales condiciones que el que llegó a establecerse en la calle 33 en el Vedado. (Diario de la Marina, 16 de marzo de 1927, p. 21e; BVPH).

(79) [1927] EL CINÓDROMO DE MARIANAO / El general Baldomero Acosta, alcalde municipal de Marianao, remitió acuerdos tomados en la sesión

\footnotetext{
34 "El nombramiento de Comisarios corresponde al Comité del «Club Deportivo Galguero» o, por delegación del mismo, a otra Sociedad que organice las carreras, cuando se trate de canódromos fuera de Madrid" (cap. XII, art. 67, Heraldo Deportivo, 5 de agosto de 1930, p. 300b; HDBN), "Los Comisarios de carreras deben: [...] 4. ${ }^{\circ}$ Tomar en el canódromo las disposiciones necesarias para el buen funcionamiento y regularidad de las carreras" (ibíd., art. 71, p. 300c; HDBN), "Los Comisarios del «Club Deportivo Galguero» tienen jurisdicción en todos los canódromos en que este Código se halle en vigor" (cap. XIII, art. 75, ibíd., 15 de agosto de 1930, p. 311c; HDBN) y "Los Comisarios del «Club Deportivo Galguero» pueden: [...] 7..$^{\circ}$ Tomar las medidas que crean oportuno, pudiendo llegar hasta la descalificación, con prohibición de entrar en los canódromos de España” (ibíd., art. 77, p. 312a; HDBN).
} 
extraordinaria del 11 del corriente, y cuyos acuerdos se refieren a los siguientes particulares: / Aprobar el informe de la Comisión de concejales sobre el estudio del escrito del señor Luis Pérez Terán, solicitando autorización para instalar un establecimiento público para dedicarlo a espectáculo de habilidad y destreza, con apuestas, y donde se celebrarán carreras de perros. (Diario de la Marina, 26 de mayo de 1927, p. 3f; BVPH).

(80) [1927] Cuarenta y cinco perros y nueve gatos encontró Sanidad en el domicilio de una señora que reside en la calle de Revillagigedo. Luego que nos digan que en Cuba no hay cinódromos. (Diario de la Marina, 28 de septiembre de 1927, p. $21 g$; BVPH).

Finalmente, el gobernador provincial, Antonio Ruiz, suspendió el acuerdo que había tomado el Ayuntamiento de Marianao el 11 de mayo y, en consecuencia, no se permitieron las carreras de galgos (cfr. Diario de la Marina, 3 de junio de 1927 , pp. $1 a$ y $12 f$-g; BVPH). Pese a la suspensión, hubo nuevas propuestas para construir un cinódromo en La Habana (cfr. Diario de la Marina, 5 de octubre de 1927, pp. 1a y 11a; BVPH). Finalmente, veinte años más tarde, el 12 de julio de 1951, fue inaugurado el Cinódromo de Marianao — también conocido como "Havana Greyhound Kennel Club"-, que funcionó algo más de una década. Poco después de la llegada al poder de Fidel Castro se prohibieron, nuevamente, las carreras de perros; según Castro, este tipo de establecimiento promovía el vicio de las apuestas tanto en la burguesía como en el proletariado (83). A pesar de la prohibición, la palabra cinódromo, vinculada a las vicisitudes políticas de este país, quedó grabada en la mente de los cubanos, quienes siguieron utilizándola tras la desaparición de su referente.

(81) [1941] A la persona no familiarizada con las condiciones actuales de los campos no le será fácil estimar en todo su valor este asunto del mantenimiento. Este vocablo no se refiere principalmente a la limpieza de las zanjas para retirar los desperdicios usuales y restaurar la depreciación natural, sino más bien a la cantidad considerable de destrucción que acompaña principalmente la fabricación de nuevas estructuras, desde casinos de playa hasta cinódromos. (Revista cubana Salubridad y asistencia social. Boletín oficial, 1941, vol. XLIV, p. 318a; GL).

(82) [1959] Cerca de medianoche se disparó en el Vedado y el cinódromo de la playa de Marianao. (Abc, 12 de agosto de 1959, p. 28a).

(83) [1963] Y este mismo sitio, este hermoso campo deportivo, con tantas y tantas instalaciones, y que hace apenas un año era un cinódromo, un lugar donde corrían perros, y donde venía mucha gente a apostarse el dinero aquí; iy no solo burgueses, no, sino incluso trabajadores, incluso proletarios!, porque la burguesía inculcaba sus vicios no solo a los burgueses, sino también a los trabajadores. [...] Y, por eso, la Revolución le puso término al cinódromo, libró a los pobres perros de aquellas carreras locas que daban por aquí [...], libró a mucha gente de sus vicios, y construyó pistas para que corrieran los jóvenes, para que compitieran los jóvenes, para que se desarrollaran nuestros jóvenes. Es decir, suprimió el vicio y estableció la 
virtud. (Discurso de Fidel Castro pronunciado el 22 de agosto de 1963 con motivo de la inauguración de los Primeros Juegos Deportivos Escolares Nacionales, en el Estadio de Becarios, reproducido en la revista cubana Escuela y revolución en Cuba, n. 2 (1963), p. 106a; GL).

(84) [1964-1967] — Galgos para el cinódromo. No me vayas a decir, por favor, que soy como ellos, que corro tras una liebre ilusoria. (Guillermo Cabrera Infante, Tres tristes tigres, Barcelona, Seix Barral, 1975, p. 356; CORDE).

(85) [1987] Pasan frente al Cinódromo y Rodrigo te dice: "Nunca me gustaron las carreras de perros. Yo siempre jugué a mi mano, al seguro. Nada de galgos ni de caballos. En la pista del Cinódromo corren muchachas con sudaderas rojas y blancas". (Manuel Cofiño, Amor a sombra y sol, La Habana, Letras Cubanas, 1987, p. 255; GL).

(86) [1999] En 1947, empezó a trabajar en la red de restaurantes y cabarets de La Habana; cantinero en Caracas, Venezuela, en 1950; para volver y emplearse en el Cinódromo de la Playa de Marianao, siendo uno de los primeros gastronómicos que trabajó en los hoteles "Havana Hilton", "Flamingo" y "Deauville". (Enrique Cirules, escritor cubano, Mafia y mafiosos en La Habana, Madrid, Ediciones Libertarias, 1999, p. 294; GL).

\subsection{Canódromo}

Canódromo es la última palabra a la que debemos referirnos. Ha de advertirse, en primer lugar, que existe un texto español de 1906 que contiene dicha voz, pero no se trata de la que aquí estudiamos, sino de un galicismo crudo homónimo procedente de canodrome, suma del francés canot y -drome, es decir, un circuito para hacer carreras de botes, de canoas:

(87) [1906] Un canodromo en Ablon. —Las regatas de botes a gran distancia ofrecen casi siempre un grave inconveniente, el de que no interesan al público, que ve partir a los corredores y los ve, o no los ve regresar, al cabo de algún tiempo, sin poder distinguir cuáles son los vencedores. Para remediar tal estado de cosas y contribuir al mismo tiempo a popula[ri]zar el bote automóvil, M. G. Itasbe, redactor comercial de Yachting Gazette, ha concebido la idea de establecer en las cercanías de París un canodromo, donde las embarcaciones competidores puedan correr sin inconveniente a la vista del público. (Revista Vida Marítima, 20 de abril de 1906, p. 215a; HDBN).

La prensa francesa había anunciado algo más de un mes antes lo siguiente:

(88) [1906] Canodrome à Ablon. - Un sportsman de la première heure, M. Itasse, vient de concevoir l'idée de créer un canodrome et de trouver le lieu qui convient à la réalisation de ce projet : la propriété de l'Union des tirs et sports d'Ablon, à 300 mètres de la gare d'Ablon, sur les bords de la Seine, au-dessous de Villejuif, en face de Villeneuve-Saint-Georges. Un lac d'eau limpide de 20 hectares s'offre comme canodrome ; son chenal permet aux canots d'arriver sans transbordement. (L'Aurore littéraire, artistique, sociale, 2 de marzo de 1906, p. 4a; Gallica). 
A mediados de los años veinte comienza a utilizarse en español la palabra canódromo, referida, ahora sí, a las pistas acondicionadas para las carreras de galgos. Importa indicar que en los primeros años de aclimatación en español se llegó a utilizar, si bien de forma ocasional, la variante canídromo. Uno de los textos citados (4) contenía esta forma; a continuación se muestran otros —nótese que el texto 92 pertenece al español de Filipinas-:

(89) [1928] En menos de un año se han construido en Inglaterra una serie de canídromos. (El Sol, 28 de abril de 1928, p. 1e; HDBN).

(90) [1930] Detrás de esa cortina la ciudad cosmopolita y la ciudad china se extienden muy lejos, más allá de aquel famoso "canídromo", donde los jugadores apuestan por los grandes lebreles. (La Correspondencia de Valencia, 17 de septiembre de 1930, p. 1a; BVPH).

(91) [1930] Por si fuera poco el interés que de por sí despiertan las consabidas seis carreras, el "match" "Solicitor"--'Ojos Ansiosos" [dos de los mejores galgos de la época] es lo suficiente para que el canídromo se vea tan animado como de costumbre. (Gran Sport. Diario de todos los deportes, 22 de octubre de 1930, p. 4b; BVPH).

(92) [1933] CANÍDROMOS / La verdad es que nadie sabía que por autorización de la legislatura dentro de algún tiempo tendremos en Manila, y acaso en otras ciudades del Archipiélago, canídromos que nos harán la vida más alegre y juguetona. (La Vanguardia. Diario filipino independiente, 6 de febrero de 1933, p. 4a; BVPH) ${ }^{35}$.

Téngase en cuenta que a lo largo de su historia el español ha conocido no pocas voces que comienzan, precisamente, por cani-: canicidalcanicidio, canícula, canicular, caniculario, canicultor/canicultura, cánido, caniforme, caninero, caninez, canino, etc. (cfr. Corominas, 1980-1991: I, s. v. can). Por otro lado, la palabra canídromo también se emplea — junto con cinódromo- en portugués, normalmente para referirse a la pista de carreras de perros de Macau, ciudad china que fue colonia del imperio portugués hasta 1999: "Cinco casinos, um canídromo e um hipódromo concentram as atenções dos jogadores" (Gualdino Paredes, Abrir joco, Lisboa, Amigos do Livro, 1985, p. 32b; GL).

Queda dicho más arriba que la palabra cinòdrom comenzó a utilizarse en catalán fundamentalmente a partir de 1975, pero es llamativo que así sucediera; aunque ahí estaban, desde luego, los modelos francés (cynodrome) e italiano (cinodromo), y quizá el del español de Cuba (cinódromo), el modelo más próximo, e incluso "natural" — por tratarse de un territorio bilingüe-, era el del nombre

35 En 1878 se documenta, de manera aislada y con marcado carácter humorístico, la palabra canídromo en el "semanario recreativo, artístico y literario" Fray Verás; naturalmente, el referente de esta voz nada tiene que ver con las pistas de carreras de perros tras liebre mecánica: "Si progresamos o no, para muestra basta un botón. Después del celebrado hipódromo de Madrid, se ha establecido en Zaragoza un borricódromo, y un canídromo en Valencia. Al paso que vamos tendremos pronto pavídromos y gatídromos" (Fray Verás, 13 de abril de 1878, p. 4a; HDBN). 
español canódromo, que, en efecto, fue el que prosperó pronto en catalán con las adaptaciones fonéticas pertinentes ${ }^{36}$ :

(93) [1932] Aclarit el cas, però, resultà no ésser absolutament cert, ja que si bé havia de córrer un tal Fina, no era pas, como s'havia cregut equivocadament, el conegut periodista, sinó un "galgo" que prenia part en unes carreres canines que se celebraven el mateix dia al canòdrom de Vallejo (Barcelona, La Rambla, 7 de marzo de 1932, p. 6b; ARCA).

(94) [1935] CANÒDROM GUINARDÓ / Darrera de l'Hospital de Sant Pau / Demà, dimarts, a la nit / CURSA DE LLEBRERS. (Full oficial del dilluns de Barcelona, 22 de julio de 1935, p. 1a; BVPH).

(95) [1968] Els treballadors de tot aquest sector, arrencant uns del Passeig de Fabra i Puig, altres del Canòdrom Meridiana. (Treball, n. ${ }^{\circ}$ 297, mayo de 1968, p. $3 b$; BVPH).

(96) [1979] [...] amb la ferocitat de sempre sense saber que qui corria davant era com la llebre metàl-lica que els gossos encalcen debades al canòdrom. (Antoni Serra, El cap dins el cercle, Barcelona, Laia, 1979, p. 210; GL).

(97) [2016] En segon lloc, no s'entén la utilització de cap animal a la competició, ni els cavalls. No té sentit. I no es tracta de prohibir els canòdroms, ni els hipòdroms, però dins de l'àmbit dels Jocs no hi haurien de ser. (Diari de Girona, 26 de agosto de 2016, p. 22a; AMG).

Mostramos a continuación, para terminar, algunos de los primeros testimonios que hemos documentado de canódromo en español —adviértase, en el texto 98, el comentario en francés que hace el periodista, anónimo, en torno a la voz $\mathrm{ca}$ nódromo; ¿sería esta la primera vez que se utilizaba la palabra en español?_ 37 :

(98) [1926] ¡CANÓDROMOS! / ¿Substituirán algún día en las pistas de carreras los canes a los caballos? [...] Las grandes pistas de carreras se convierten en canódramos [sic] (pas[s]ez, le mot). (La Esfera, 28 de agosto de 1926 , p. 33a; HDBN).

(99) [1927] Las pruebas finales de la copa ofrecida por S. M. el Rey D. Alfonso XIII para las carreras de galgos en el Estadio White City terminaron con la victoria del galgo Manowar. [...] La Sociedad formada para la explotación del Estadio de Wembley, para transformarlo en un canódromo, ha adquirido una importancia que no se podría sospechar. ( $A b c, 27$ de agosto de 1927, p. 28a).

(100) [1927] La Grey-hound Racing Association es la suprema autoridad en la materia y la que organiza los grandes premios oficiales de las distintas categorías, que se repartirán por turno riguroso entre los múltiples canódromos que respeten su reglamento y aporten determinada cantidad para el sostenimiento de la Asociación. (Blanco y Negro, 20 de noviembre de 1927, p. [73a]; Abc).

36 AMG recupera 900 textos en los que se documenta la voz canòdrom $(s)$, comprendidos en el periodo 1934-2016; ARCA (253 textos, periodo 1932-1939); BVPH (83 textos, 1934-2010); PDGC (5 textos, periodo 1934-2001).

37 A continuación se indica la fecha de la primera documentación que ofrecen los corpus y otras fuentes de información manejados (solo se recogen los que presentan información relevante sobre la 1. a doc.): HDBN (1926), BVPH (1926), Abc (1927), La Vanguardia (1932), CORDE (1937), CNDH (1937), Fich. Ac. (1947). 
(101) [1927] Rubyk, por su lado, literariamente encomiaba la importancia que desde remotos tiempos tiene el caballo, y lanzaba la interrogación sobre si el canódromo terminaría con el hipódromo. (Heraldo deportivo, 5 de diciembre de 1927, p. 535a; HDBN).

(102) [1927] Londres.-Aspecto parcial del estadio de Wembley, convertido en canódromo, el día de la inauguración de las carreras de galgos en esta temporada, que fueron presenciadas por más de 70.000 espectadores [pie de foto]. [...] En Inglaterra $-\mathrm{y}$ aun en Francia, a cuya capital ya ha llegado el espectáculo- las carreras de galgos no representan sino un magnífico negocio descubierto por un avisado promotor, al que han imitado rápidamente los ciento y pico que se han apresurado a abrir canódromos en distintas ciudades importantes para que el gran público pueda regocijarse con la distracción ahora favorita. [...] Resulta indudable que vive prósperamente una organización creada en poco menos de un año al amparo de la tolerancia de los canódromos. [...] Un grupo de aficionados (?) ha adquirido el soberbio estadio de Wembley, con capacidad para cien mil espectadores, y le ha convertido en el más formidable canódromo inglés, recientemente inaugurado. (Mundo Gráfico, 28 de diciembre de 1927, pp. $7 a$ y $8 a$; HDBN).

A excepción de Cuba y México, que, como hemos visto, se decantaron, respectivamente, por cinódromo y galgódromo, el sustantivo canódromo se difundió por otros países hispanoamericanos como Argentina, Bolivia, Chile, Colombia, Perú, Puerto Rico, República Dominicana, Uruguay y Venezuela ${ }^{38}$.

\section{CONCLUSIONES}

A tenor de lo expuesto, podemos afirmar que en un primer periodo, de entre ocho y diez años, en el que se comenzaba a hablar en español de las carreras de perros en pista, sus hablantes pusieron en circulación cuatro voces sinónimas con las que referirse a esa pista o instalación preparada para las carreras de perros. Dejando al margen la voz perródromo, que apenas tuvo fortuna, la rivalidad efectiva se produjo entre canódromo, cinódromo y galgódromo. Esta última pronto fue cediendo terreno a las dos primeras y, al menos en la Península ${ }^{39}$, no superó los primeros años treinta. Las fuentes de datos consultadas así lo prueban. La HDBN recupera veinticinco testimonios de la palabra galgódromo para el periodo 1928-1935, y cua-

${ }^{38}$ Pueden obtenerse textos de dichos países en CORDE, CREA, CORPES, Davies, GL, La Nación, etc. Debe indicarse que el Diccionario de americanismos (2010) recoge la forma dromo como sustantivo propio de la República Dominicana, con el significado "Lugar donde se celebran competencias de perros"; sin embargo, tras consultar las fuentes de que nos hemos servido en este trabajo, no se ha localizado texto alguno que avale este uso.

39 Recuérdese lo que queda dicho en el apartado § 3.2, donde se muestra que el sustantivo galgódromo arraigó en el español de México. 
tro más entre los años 1994 y 2001. La BVPH nos ofrece seis textos con la misma voz (periodo 1927-1932), y uno más de 1984 (cfr. cita 37). La búsqueda, en fin, en la hemeroteca del diario $A b c$ recupera cinco textos de galgódromo para el periodo 1927-1931, y uno más del año 2004. Los testimonios que ofrecen tales hemerotecas pertenecen, fundamentalmente, a textos publicados entre 1927 y 1933, y solo de manera ocasional se documenta la voz galgódromo en textos posteriores.

La verdadera pugna léxica se libró, en consecuencia, entre canódromo y cinódromo. Tal y como muestran los muchos testimonios considerados entre 1927 y $1935^{40}$, ambas voces habían gozado de una extraordinaria acogida entre los hablantes durante dicho periodo. Sin embargo, en los años treinta comienza a observarse una clara preferencia por canódromo y un descenso paulatino en el uso de cinódromo. Aunque son numerosísimos — se cuentan por millares - los textos que a partir de los años treinta y hasta nuestros días contienen la voz que terminó imponiéndose, estimamos oportuno mostrar unos datos que manifiestan a las claras este apabullante éxito. La búsqueda de la palabra cinódromo en la hemeroteca del diario $A b c$ recupera tan solo seis textos, mientras que la del nombre canódromo ofrece más de dieciséis mil. Por su parte, la hemeroteca de La Vanguardia, aunque no llega a esta cifra, permite recuperar más de tres mil textos que contienen tanto canódromo como canòdrom. Según estos periódicos, entre los años sesenta y ochenta la palabra canódromo experimentó su periodo de máxima utilización, y a partir de los noventa su uso sufrió un importante retroceso que, sin duda, estuvo motivado por el paulatino cierre de pistas de carreras de galgos en España ${ }^{41}$; dicho de otro modo, una de las causas del descenso en el empleo de canódromo en las dos últimas décadas ha sido el cierre o la desaparición del referente de dicha voz. Esto no quiere decir, obviamente, que la palabra canódromo haya dejado de usarse en el español peninsular, pero sí da cuenta de la íntima relación entre la vigencia $-\mathrm{y}$, en el caso que nos ha ocupado, también la popularidad - de la realidad extralingüística (el referente) y el signo linguiístico que la designa. Aunque es natural que la desaparición de una realidad sea un factor decisivo que determine la obsolescencia de una voz, e incluso en ocasiones su pérdida, la voz canódromo, a pesar de su manifiesto descenso en el uso, no se encuentra, ni mucho menos, en vías de desaparecer en España, entre otros motivos por la necesidad designativa de nombrar, cuando la comunicación lo requiera, las pistas de carreras de perros existentes en otros países.

\footnotetext{
40 Pueden obtenerse muchos otros textos en la HDBN.

41 La consulta de otras hemerotecas digitales ofrece resultados semejantes. La BVPH recupera en torno a dos mil textos que contienen la voz canódromo. En el periodo 1926-1998, el $40 \%$ de los textos se concentra en los años sesenta y setenta. Según este recurso, también es muy notable el uso de dicha voz en los años treinta $(25 \%)$. Igualmente, la HDBN, que contiene más de treinta y un mil textos con la palabra canódromo en el periodo 1926-1999, muestra que los años sesenta, setenta y ochenta representan el 78,8 \% de las ocurrencias (respectivamente, 22,8 \%, 32,9 \% y 23,1\%).
} 


\section{CORPUS Y FUENTES DE DATOS}

$A b c=$ Hemeroteca del $A b c$ [en línea] <http://hemeroteca.abc.es $>$.

$\mathrm{AMC}=$ Ayuntamiento de Cartagena: Archivo Municipal de Cartagena [en línea] $<$ https://archivo.cartagena.es $>$.

$\mathrm{AMG}=$ Ajuntament de Girona: Arxiu Municipal de Girona [en línea] $<$ http://www.girona.cat/sgdap/cat/index.php>.

ARCA = Biblioteca de Catalunya: Arxiu de Revistes Catalanes Antigues [en línea] $<$ https://arca.bnc.cat/arcabib_pro/ca/inicio/inicio.do $>$.

$\mathrm{BDH}=$ Biblioteca Nacional de España: Biblioteca Digital Hispánica [en línea] $<\mathrm{http} / / / w w w . b n e . e s /$ es/Catalogos/BibliotecaDigitalHispanica/Inicio/>.

$\mathrm{BDMM}=$ Ayuntamiento de Madrid: Biblioteca Digital memoriademadrid [en línea] $<\mathrm{http}: / / \mathrm{www}$.memoriademadrid.es $>$.

BVCLM = Universidad de Castilla-La Mancha/Centro de Estudios Castilla-La Mancha: Biblioteca Virtual de Castilla-La Mancha [en línea] <https://www.uclm.es/centrosinvestigacion/ceclm>.

BVPH = Ministerio de Educación, Cultura y Deporte: Biblioteca Virtual de Prensa Histórica [en línea] <http://prensahistorica.mcu.es/es/consulta/busqueda.cmd>.

$\mathrm{CNDH}=$ Instituto de Investigación Rafael Lapesa de la Real Academia Española: Corpus del Nuevo diccionario histórico [en línea] <http://web.frl.es/CNDHE>.

CORDE = Real Academia Española: Banco de datos (CORDE) [en línea]. Corpus diacrónico del español, <http://www.rae.es>.

CORDIAM = Academia Mexicana de la Lengua, Corpus Diacrónico y Diatópico del Español de América [en línea] <www.cordiam.org>.

CORPES = Real Academia Española: Banco de datos (CORPES) [en línea]. Corpus del español del siglo XXI, <http://www.rae.es>.

CREA = Real Academia Española: Banco de datos (CREA) [en línea]. Corpus de referencia del español actual, <http://www.rae.es>.

$\mathrm{CV}=$ Biblioteca Virtual Miguel de Cervantes: Cervantes Virtual [en línea] $<$ www.cervantesvirtual.com $>$.

Davies = Mark Davies: Corpus de Español: Web/Dialectos [en línea] <https://www. corpusdelespanol.org/web-dial/>.

Fich. Ac. = Real Academia Española: Fichero general [en línea] <http://www.rae.es $>$.

Folha = Folha de S. Paulo: Acervo Folha: $<$ https://acervo.folha.com.br/index.do $>$.

Gallica = Bibliothèque nationale de France: Gallica [en línea] <https://gallica.bnf.fr/html/ und/presse-et-revues/presse-et-revues $>$.

$\mathrm{GL}=$ Google: Google Libros [en línea] <https://books.google.es> .

$\mathrm{GM}=$ Agencia Estatal Boletín Oficial del Estado: Gaceta de Madrid [en línea] <https:// www.boe.es/buscar/gazeta.php>.

HDBN = Biblioteca Nacional de España: Hemeroteca Digital [en línea] <http:// hemerotecadigital.bne.es/index.vm>.

HNDM = Universidad Nacional Autónoma de México, Hemeroteca Nacional Digital de México [en línea] <http://www.hndm.unam.mx/index.php/es/>.

$\mathrm{HPC}=$ Archivo General de la Provincia de Santa Fe (Argentina), Hemeroteca Digital «Fray Francisco de Paula Castañeda» [en línea] <http://www.santafe.gov.ar/ hemerotecadigital/articulo/portada/>.

La Nación = Hemeroteca del diario argentino La Nación [en línea] <https://buscar. lanacion.com.ar>. 
PDGC $=$ Generalitat de Catalunya, Premsa Digitalitzada [en línea] <http://xacpremsa. cultura.gencat.cat/pandora/\#top>.

La Stampa $=$ La Stampa. Archivio Storico dal 1867 [en línea] <http://www. archiviolastampa.it/component/option,com_frontpage/Itemid,1/>.

La Vanguardia $=$ Hemeroteca de La Vanguardia [en línea] <https://www.lavanguardia. com/hemeroteca>.

\section{BIBLIOGRAFÍA}

Academia Mexicana de la Lengua (2010): Diccionario de mexicanismos, Ciudad de México, Siglo XXI.

Alcover, Antoni Maria y Francesc de Borja Moll (1930-1962): Diccionari català-valencià-balear, 10 vols., Palma de Mallorca, Moll.

Asociación de Academias de la Lengua Española (2010): Diccionario de americanismos, Madrid, Santillana.

Battaglia, Salvatore (1961-2002): Grande dizionario della lingua italiana, 21 vols., Torino, Unione Tipografico-Editrice Torinese.

Boyd-Bowman, Peter M. (1997-1998): "Difusión y popularización, en la Hispanoamérica actual, de ciertos morfemas griegos y latinos", Cauce. Revista Filología y su Didáctica, 20-21, pp. 45-58.

Boyd-Bowman, Peter M. (2007): Léxico hispanoamericano, 1493-1993, Ray Harris-Northall y John J. Nitti (eds.), New York, Hispanic Seminary of Medieval Studies, 2003. [Manejamos la versión 2.10 de abril de 2007, en línea: <https://textred.spanport.wisc.edu/lexico_hispanoamericano/ index.html >].

Carreras i Martín, Joan (dir.) (1981): Gran enciclopèdia catalana, Barcelona, Enciclopèdia Catalana, vol. 5.

Cervantes Saavedra, Miguel de (1613): Novela del licenciado Vidriera, en Novelas exemplares, Madrid, Juan de la Cuesta.

Corominas, Joan (1980-1991): Diccionario crítico etimológico castellano e hispánico, Madrid, Gredos, 6 vols. [Con la colaboración de José A. Pascual].

Corominas, Joan (1991-1995): Diccionari etimològic $i$ complementari de la llengua catalana, $6{ }^{\mathrm{a}}$ ed., Barcelona, Curial Edicions Catalanes/Caixa de Pensions «La Caixa», 9 vols. [Con la colaboración de Joseph Gulsoy y Max Cahner].

Genders, Roy (1981): The Encyclopaedia of Greyhound Racing. A Complete History of the Sport, London, Pelham.

Hartwell, Paul C. (1980): The Road from Emeryville. A History of Greyhound Racing, San Diego (California), California Research Publishing.

Herrero Mayor, Avelino (1947): Apuntaciones lexicográficas y gramaticales. Más de mil anotaciones etimológicas, semánticas, prosódicas y sintácticas, Buenos Aires, Kapelusz.

Institut d'Estudis Catalans (1995): Diccionari de la llengua catalana, Barcelona, Enciclopèdia Catalana.

Knight, Victor (2003): Greyhound Racing to Win, Harpenden (Inglaterra), High Stakes.

Levinson, David y Karen Christensen (eds.) (1999): Encyclopedia of World Sport. From Ancient Times to the Present, New York/Oxford, Oxford University Press.

$N G L E=$ Real Academia Española/Asociación de Academias de la Lengua Española (2009): Nueva gramática de la lengua española, 2 vols., Madrid, Espasa Libros.

NTLLE = Real Academia Española (2001): Nuevo Tesoro Lexicográfico de la Lengua Española, Madrid. Edición en 2 DVD [también en línea] <http://www.rae.es>.

$O E D=$ Murray, J. A. H. et al. (dir.) (1884-1928): The Oxford English Dictionary, Oxford, Oxford University Press, 12 vols. [Más un suplemento, publicado en 1933]. 
OED Suppl. = Burchfield, R. W. (dir.) (1972-1986): A Supplement to the Oxford English Dictionary, Oxford, Oxford University Press, 4 vols.

Pharies, David (2002): Diccionario etimológico de los sufijos españoles y de otros elementos finales, Madrid, Gredos.

Rainer, Franz (1993): Spanische Wortbildungslehre, Tübingen, Niemeyer.

Real Academia Española (1970): Diccionario de la lengua española, 19. ${ }^{a}$ ed., Madrid, EspasaCalpe.

Real Academia Española (2014): Diccionario de la lengua española, 23. ${ }^{a}$ ed., Madrid, Espasa.

Robert, Paul (1966-1978): Dictionnaire alphabétique et analogique de la langue française. Le mots et les associations d'idées, 7 vols., Paris, Société du nouveau Littré/Le Robert.

Rollin, Nicholas, Carol Styles Carvajal y Jane Horwood (dirs.) (2013): Compact Oxford Spanish Dictionary: Spanish-English, English-Spanish, Oxford, Oxford University Press.

Temple, Robert (2011): The History of Greyhound Racing in New England, [Bloomington, Indiana], Xlibris Corporation.

The Encyclopadia Britannica (1932): London/New York, 14. ${ }^{a}$ ed., vol. 10.

Thompson, William N. (2015): Gambling in America. An Encyclopedia of History, Issues, and Society, 2. ${ }^{a}$ ed., Santa Barbara/Denver/Oxford, ABC-CLIO.

Trésor de la langue française. Dictionnarie de la langue du XIXe et du XXe siècle (1789-1960) (1971-1994): publicado bajo la dirección de Paul Imbs, 16 vols., París, CNRS.

Wilcox, Charlotte (2001): The Greyhound, Mankato (Minnesota), Capstone Press.

Zavala, José María (2013): La pasión de Pilar Primo de Rivera, Barcelona, Plaza \& Janés.

Fecha de recepción: 10 de septiembre de 2018

Fecha de aceptación: 16 de mayo de 2019 
